LINKÖPING STUDIES IN SCIENCE AND TECHNOLOGY.

LICENTIATE THESIS, NO. 1692

ANDREAS BJÖRNSSON

\title{
ENABLING AUTOMATION OF COMPOSITE MANUFACTURING THROUGH THE USE OF OFF-THE-SHELF SOLUTIONS
}


ISBN 978-91-7519-183-6

ISSN 0280-7971

Copyright $(\mathbb{C}$ Andreas Björnsson

andreas.bjornsson@liu.se

URL: www.iei.liu.se/indprod

Published and distributed by:

Division of Manufacturing Engineering

Department of Management and Engineering

Linköping University

58183 Linköping

Sweden

Printed by

LiU-Tryck, Linköping 2014 


\section{ABSTRACT}

Composite materials offer an appealing combination of low weight and high strength that is especially sought after in high-performance applications. The use of composite materials has and is continuing to increase, and the use of the material has been shown to provide substantial weight savings in for example aircraft design. With an increased use of composite materials follows an increased demand for cost-efficient manufacturing methods.

Composite products are in many cases manufactured either by manual operations or by the use of complex automated solutions associated with high investment costs. The objective for this research is to explore an approach to develop automated composite manufacturing based on commercially available off-theshelf solutions as an alternative to the existing automated solutions for composite manufacturing.

The research, which was carried out in collaboration with industrial partners within the aerospace sector, is based on a demonstrator-centered research approach. Three conceptual demonstrators, focusing on three different manufacturing methods and a number of physical demonstrators, are used to show that off-the-shelf solutions can be used for automated manufacturing of composite products.

Two aspects that affect if it is possible to use off-the-shelf solutions for automated composite manufacturing are the rigorous quality standards used by the aerospace industry and the great variety in product properties and material properties that is associated with composite manufacturing.

The advantages in using off-the-shelf solutions has shown to be that the solutions generally are associated with low investments and that published information about the solutions, and the solutions themselves, is generally available for evaluation and testing. When working with the demonstrators it has been shown to be useful to break down a manufacturing system into basic tasks and consider off-the-shelf solutions for each particular task. This approach facilitates the search for a suitable off-the-shelf solution to solve a particular task. However, each of the separate tasks can affect other areas of the manufacturing system, and an overall systems perspective is required to find solutions that are compatible with the entire manufacturing system. 



\section{ACKNOWLEDGMENTS}

First of all I would like to thank my supervisor, Dr. Kerstin Johansen, who introduced me to the notion of becoming a scientist and later recruited me to a $\mathrm{PhD}$ position. Kerstin has shown me the research perspective on manufacturing engineering, introduced me to her vast network of contacts both in industry and academia, and continuously supported my research endeavor. I would also like to acknowledge the contributions made by my other supervisor, Prof. Mats Björkman. I'm also very grateful for all the support I have received from Dr. Marie Jonsson, who has contributed with technical knowledge as well as views on research approach and methodology.

Since the research presented herein is within the field of manufacturing engineering many of the results, quite naturally, stem from close collaboration with a number of industrial partners in several research projects. I would like to thank all the industrial partners for investing both time and resources in these research projects. It is impossible to mention all the industrial partners, but among them that have contributed to the presented research are Jan Erik Lindbäck at Saab Aerostructures, Mats Eklund and Dan Alexandersson at GKN Aerospace Applied Composites $\mathrm{AB}$, and Leif Håkansson and Michael Thuswaldner at RUAG Space AB. The research would not have been possible without funding by Vinnova's Strategic Vehicle Research Program, Vinnova's National Aviation Engineering and Research Program, and the Swedish National Space Board. Some of the work included in the licentiate thesis has been conducted as a parttime employee of the Compraser research organization. Compraser and Kjell Sullivan are greatly acknowledged for their support.

I'm fortunate to be surrounded by great colleagues, the discussions that we have concerning research, teaching and life in general are inspiring and make work highly enjoyable. I would especially like to thank Sebastian von Gegerfelt and Rickard Olsen for always helping me in the lab, and Kristofer Elo for generously giving me the typographical template used in the licentiate thesis.

Finally, I would like to thank my family and friends for always supporting me. My deepest gratitude goes to Jenny, my partner in life, who is my inspiration and source of energy.

Linköping, October 2014

Andreas Björnsson 



\section{APPENDED PAPERS}

\section{Paper I}

Björnsson, A., Lindbäck, J. E., \& Johansen, K (2013). "Automated Removal of Prepreg Backing Paper - A Sticky Problem" in Proceedings of the SAE 2013 Aerotech Congress and Exhibition, $24^{\text {th }}-26^{\text {th }}$ September 2013, Montreal, Canada, peer-reviewed.

\section{Paper II}

Björnsson, A., Johansen, K., \& Alexandersson, D. (2013) "Three-Dimensional Ultrasonic Cutting of RTM Preforms - A Part of a High Volume Production System" in Proceedings of the $19^{\text {th }}$ International Conference on Composite Materials, $28^{\text {th }}$ July - $2^{\text {nd }}$ August 2013, Montreal, Canada, peer-reviewed.

\section{Paper III}

Björnsson, A., Thuswaldner, M., \& Johansen, K. (2014) "Automated Composite Manufacturing Using Off-The-Shelf Automation Equipment - A Case from the Space Industry" in Proceedings of the $16^{\text {th }}$ European Conference on Composite Materials, $22^{\text {nd }}-26^{\text {th }}$ June 2014 , Seville, Spain.

\section{Paper IV}

Björnsson, A. \& Johansen, K. (2012) "Composite Manufacturing: How Improvement Work Might Lead to Renewed Product Validation" in Proceedings of the Swedish Production Symposium 2012 (SPS12), $6^{\text {th }}-8^{\text {th }}$ November 2012, Linköping, Sweden, peer-reviewed.

\section{OTHER PUBLICATIONS}

\section{Paper V}

Lindbäck, J. E., Björnsson, A., \& Johansen, K. (2012) "New Automated Composite Manufacturing Process: Is it possible to find a cost effective manufacturing method with the use of robotic equipment?" in Proceedings of the Swedish Production Symposium 2012 (SPS12), 6th-8th November 2012, Linköping, Sweden, peer-reviewed. 



\section{TABLE OF CONTENTS}

1 Introduction.......................................................................... 1

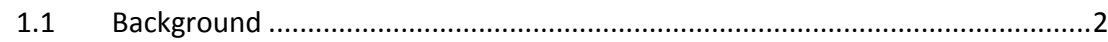

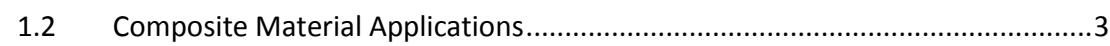

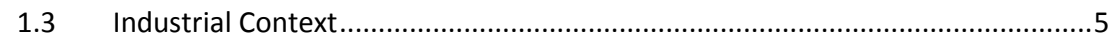

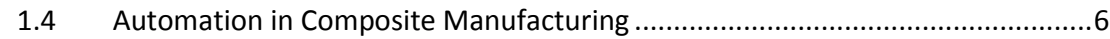

1.5 Off-the-shelf Solutions ...............................................................................

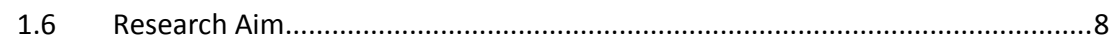

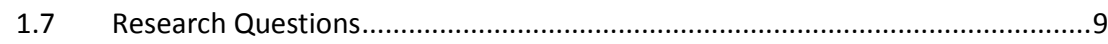

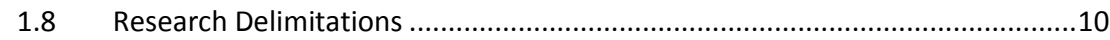

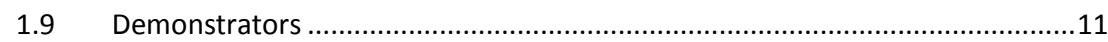

2 Research Methodology ......................................................... 13

2.1 Research Approaches and Research Methodologies.....................................15

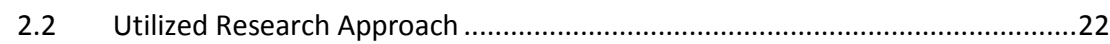

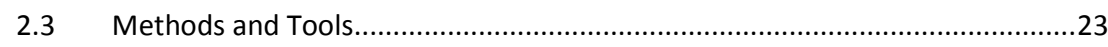

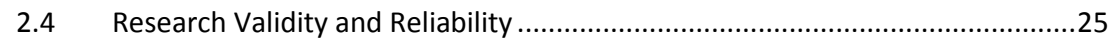

2.5 Research Environment and Research Projects ................................................2.

3 Theoretical Foundation ............................................................... 31

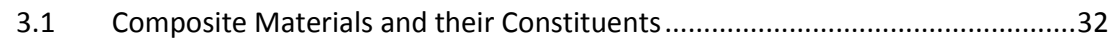

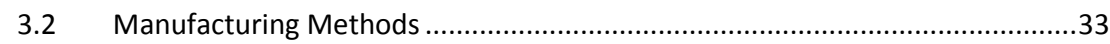

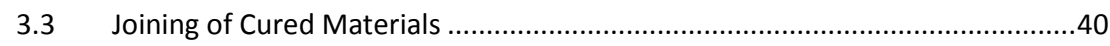

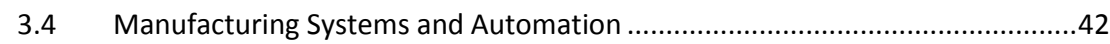

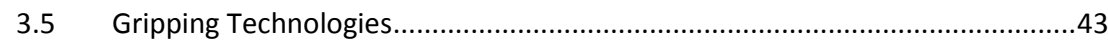

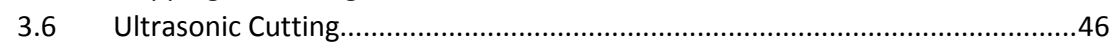

4 Research Results ................................................................. 47

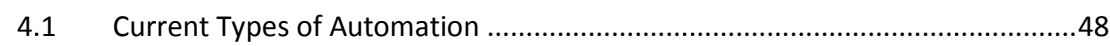

4.2 Conceptual Demonstrator 1: Automated Layup of Flat Laminates ...................51

4.3 Conceptual Demonstrator 2: Automated Manufacturing of Preforms...............57

4.4 Conceptual Demonstrator 3: Adhesive Joining of Cured Material ....................60

4.5 Implementing Off-the-shelf Solutions.............................................................65

5 Conclusions and Discussion ................................................... 71

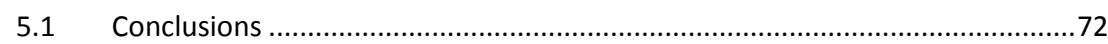

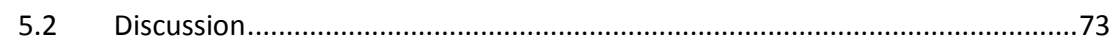

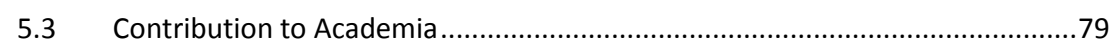

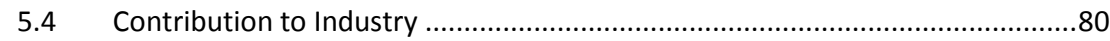

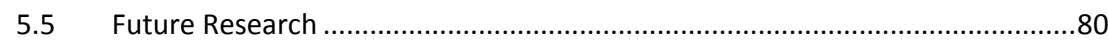

6 References ..................................................................... 83

7 Appended Papers..............................................................89 89 


\section{LIST OF FIGURES}

Figure 1: The constituents of composite materials................................................ 3

Figure 2: The global demand for carbon fiber in tons.......................................... 4

Figure 3: The global demand for CFRP in tons................................................. 4

Figure 4: The consumption of carbon fiber in different applications ...................... 5

Figure 5: Global revenues from carbon fiber in different applications. ................... 5

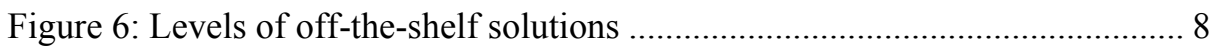

Figure 7: The two major fundaments for a conceptual demonstrator.................... 11

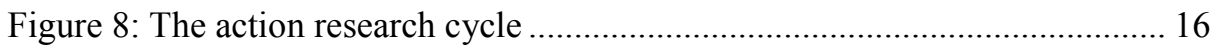

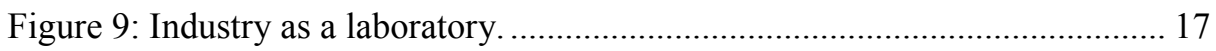

Figure 10: The four research strategies in systems development research........... 18

Figure 11: The five stages of systems development ........................................... 19

Figure 12: A demonstrator-centered research approach ....................................... 21

Figure 13: An example of test plan development ........................................... 25

Figure 14: A time line showing the research projects ........................................... 27

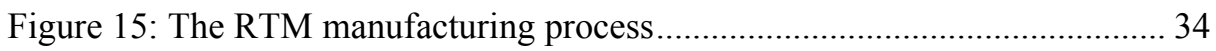

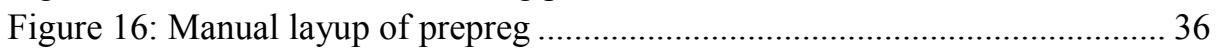

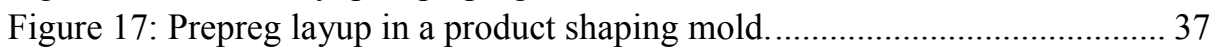

Figure 18: Prepreg layup with a separate shaping process ................................ 37

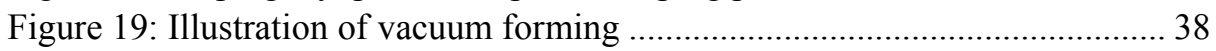

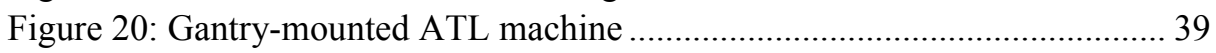

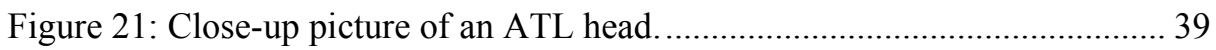

Figure 22: Prepreg with white backing paper and blue protective plastic............ 40

Figure 23: Summary of gripping technologies .................................................... 44

Figure 24: Process map of Conceptual Demonstrator 1 ................................... 53

Figure 25: The selected layout for Conceptual Demonstrator 1 1........................... 53

Figure 26: The pickup sequence for removal of the backing paper ..................... 55

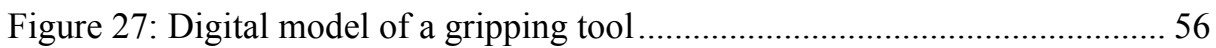

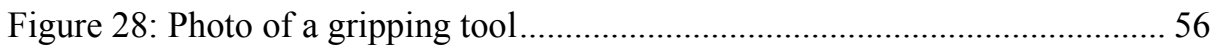

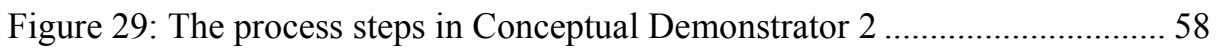

Figure 30: Layout of Conceptual Demonstrator 2 ........................................... 58

Figure 31: The demonstrator setup used for evaluating 3D ultrasonic cutting .... 59

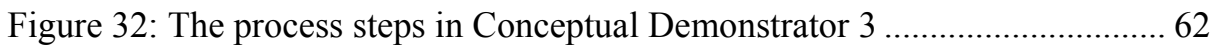

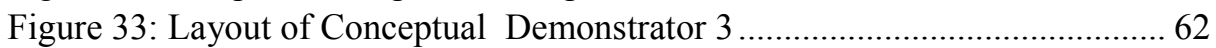

Figure 34: Voids and uncovered areas as a result of a poor dispense pattern ...... 63

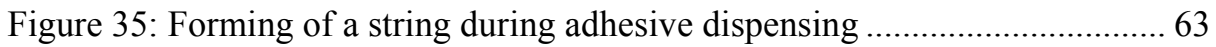

Figure 36: The physical demonstrator for adhesive application............................ 64 
Figure 37: Close-up on the gripper and the dispensing unit

Figure 38: Close-up on the mockup segment and the fixture ................................. 64

Figure 39: Illustration of contact points in vacuum gripper tool ........................... 75

\section{LIST OF TABLES}

Table 1: Connection between the research questions and the appended papers... 10

Table 2: Connection between conceptual demonstrators and appended papers... 12

Table 3: Methods for surface cleaning or surface preparation ............................... 41

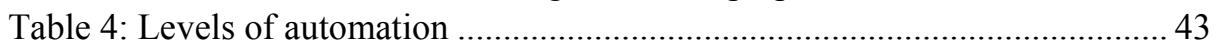

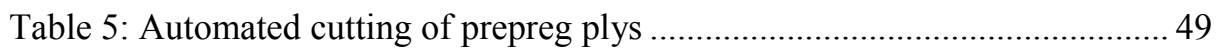

Table 6: Fraction of manual layup for four different beams................................. 52 



\section{INTRODUCTION}

In the first chapter, an introduction to the research area is given along with important definitions. Here, the research aim is presented together with the research questions and delimitations, and the appended papers' connections to the research questions are outlined. 


\subsection{BACKGROUND}

For high-performance applications, composite materials offer an appealing combination of high strength and low weight. The material properties facilitate lightweight designs that are sought after in many areas. In automobiles and aircraft, lightweight design can reduce fuel consumption and thereby contribute to reduced environmental impact. The interest in composite materials has increased during the last decades, and the use of composite materials is predicted to continue to increase in the future (Balasubramanian, 2014: Jahn, 2013). Traditionally, the focus in composite material research has been on material properties and design approaches utilizing the material's strength and stiffness in efficient ways. However, with an increased use of composite materials in areas like the automotive sector, where costs are more important than in the areas where the use of composite materials first were adopted, the need for rational, cost-efficient manufacturing methods increases. Automated manufacturing processes are, by several researchers (Jahn, 2013: Lukaszewicz et al., 2012: Åström, 1997), considered to be an important part in developing cost-efficient manufacturing of products based on composite materials.

The term composite material covers a wide field, and the definition of the term can somewhat change between different sources. A composite material is, according to Åström (1997), a combination of two or more distinct material phases into a new material where the phases are still discernible. A similar definition is made by Campbell (2004), who defines a composite material as a combination of two or more materials that result in better properties than the constituents alone. Campbell (2004) points out that each constituting material retains its separate chemical, physical and mechanical properties in the composite material. This definition is used within this licentiate thesis for the widest interpretation of the term, but the term is narrowed down further to better fit with the area in which the research is conducted.

The two major constituent elements in composite materials are matrix and reinforcement, usually in the form of fibers. The fibrous reinforcement carries most of the external load and gives the material its major strength and stiffness (Åström, 1997). The matrix binds the fibers together, transfers external loads to the fibers, protects the fibers from the surrounding environment and gives the composite material its surface appearance (Åström, 1997). Common matrix materials are polymers, metals or ceramics and some of the most common fibrous reinforcements are glass, carbon and aramid fibers. Carbon Fiber Reinforced Plastic (CFRP) is, as illustrated in Figure 1, a group of composites 
made up of a carbon fiber reinforcement combined with a polymer matrix. This group of composites is by far the most commonly encountered in the research projects described in this thesis. Therefore, the terms composite materials or composites will, in this thesis, be used as synonyms for carbon fiber reinforced plastic unless otherwise specified.

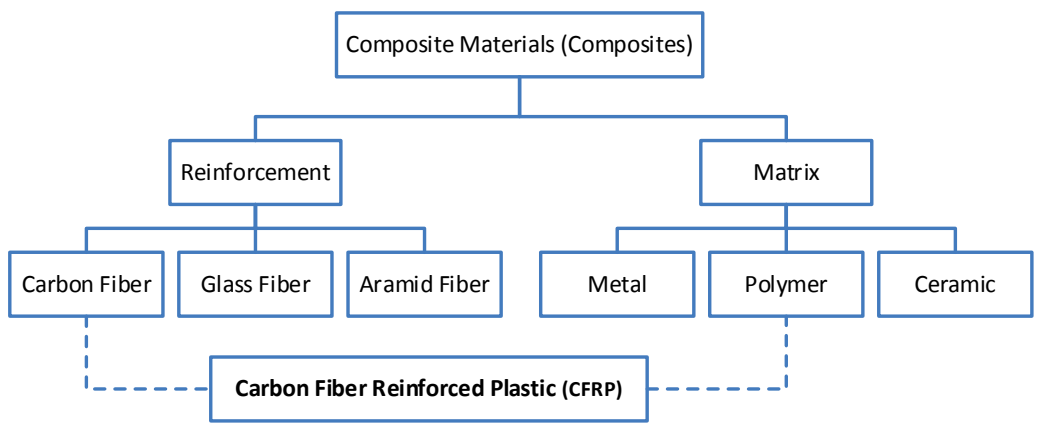

Figure 1: The constituents of composite materials.

The two major constituent elements, the matrix and the reinforcement, can, depending on what manufacturing method is being used, be handled as two separate raw materials until the final processing step. In this final processing step, the matrix and the fiber reinforcement are combined to form the composite material at the same time as the product is being produced. This is the case in, for example, molding technologies like Resin Transfer Molding (RTM). Other manufacturing technologies, like Automatic Tape Laying (ATL) and Automatic Fiber Placement (AFP) described in Chapter 3.2.2, use materials where the fibrous reinforcement has been impregnated by the matrix material in a previous processing step. This type of material, called prepreg, contains both matrix and reinforcement and is seen as a raw material for the ATL and AFP processes.

\subsection{Composite Material Applications}

The use of natural composite materials like wood, or simple composites like clay reinforced with straw, has a very long history. The use of carbon fiber reinforced plastic composites dates back to the mid-1960s, when a process to manufacture high-performance carbon fiber was developed (Dorey, 1987). The first carbon fibers were expensive and reserved for high-tech and high-cost applications (Dorey, 1987). In aircraft manufacturing, CFRP composites found their first use for stiffness-critical components for military aircraft. Their use quickly spread, however, to other types of applications and to civil aircraft (Dorey, 1987). They also found early use in space applications where 
composites are very suitable, not only for their combination of low weight and high strength, but also for their stability caused by a very low coefficient of thermal expansion (Dorey, 1987). The first applications that resulted in a high production demand for carbon fiber were the use of CFRPs in sporting goods (Dorey, 1987). Today, in the newest generations of aircraft like the Airbus A350 and Boeing 787 , around $50 \%$ of the total weight is comprised of many different types of composite materials, not only CFRP composites (Airbus, Boeing). The use of composite materials and carbon fiber reinforcement has increased over the years and is predicted to grow in the future. In a 2013 report on the global market for carbon fiber and CFRPs, Bernhard Jahn from CCeV, an association of companies and research institutes within the composites business, presented historical data as well as a prognosis. The data from the report are summarized below.

The global demand for pure carbon fiber is shown in Figure 2, while the global demand for carbon fiber reinforced plastic is shown in Figure 3. Over 97\% of the carbon fiber produced in the world is processed into some kind of composite material and most of it, around 95\%, is processed into CFRP (Jahn, 2013). The figures for CFRP are naturally higher, since the weight of the matrix material is included.

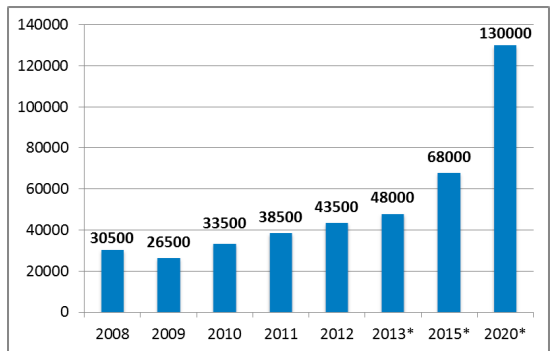

Figure 2: The global demand for carbon fiber in tons. Figures for 2013-2020 are market forecast (Jahn, 2013).

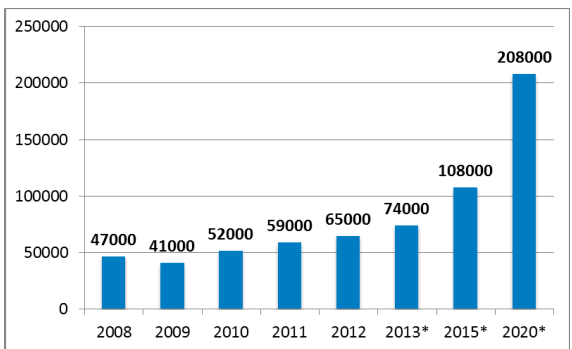

Figure 3: The global demand for CFRP in tons. Figures for 2013-2020 are market forecast. (Jahn, 2013).

Looking at the pure use of carbon fiber, in Figure 4 it can be noted that the main use, around $23 \%$ of the total demand, is for wind turbines, and in particular the rotor blades. The second largest user is the aerospace and defense sector. However, the revenue figures in Figure 5 show that the aerospace and defense sector accounts for around $40 \%$ of the global sales. This, according to Jahn (2013), is due to the high-quality standards, licenses and inspections that are required within the aerospace and defense sector and result in high material prices. 


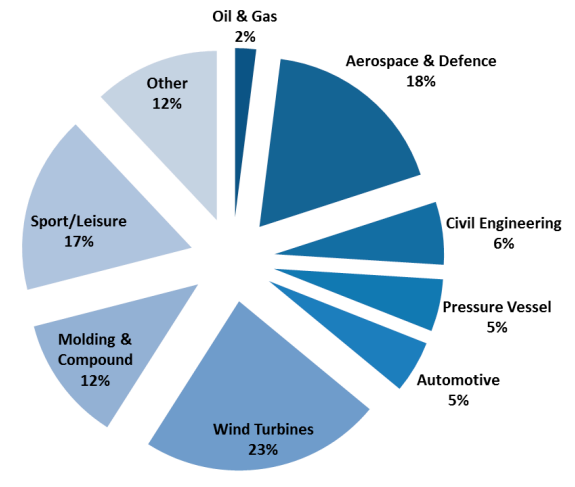

Figure 4: The consumption of carbon fiber in different applications, based on the total demand of 43,500 tons in 2012 (Jahn, 2013)

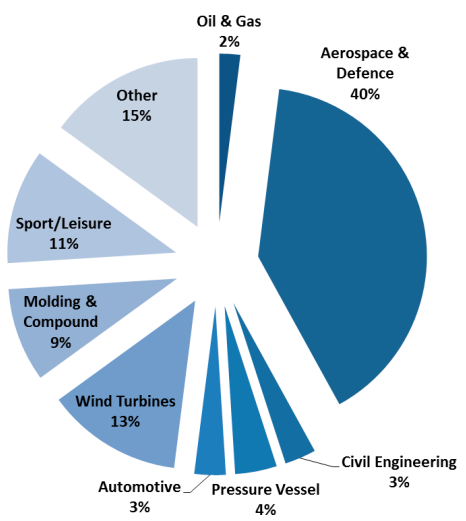

Figure 5: Global revenues from carbon fiber in different applications, based on the total value of \$2.034 billion in 2012 (Jahn, 2013).

In a report on the global carbon fiber market, Jahn (2013) provides an outlook on the future use of carbon fiber and predicts a future increase in the use of the material. There is a possibility for ecological and economic benefits by using the material for lightweight designs. However, Jahn highlights that mass production of CFRP and automation of manufacturing processes are essential to achieve increased use. This view is shared by Åström (2002), who points out that manufacturing methods and knowledge must be significantly improved to further enhance the competitiveness of composites. Lukaszewicz et al. (2012) use the two new aircraft programs mentioned previously as an example of drivers for increased production rates and improved production economy. An increased interest from other areas, like automotive and renewable energy, where composite materials can be interesting to use if they are cost competitive to their metallic counterparts, puts further demands on improvement in the manufacturing of composites. Lukaszewicz et al. (2012) argue that one way to achieve the needed developments in manufacturing is by the use of automation. This is in line with a more general trend within manufacturing where, according to Groover (2008), there is a long-term trend toward a greater use of automated machines as a substitute for manual labor.

\subsection{INDUSTRIAL CONTEXT}

The research described in this licentiate thesis has been performed in collaboration with industrial partners within the aerospace industry. The term aerospace industry is herein used as a generic term for companies that work with development and manufacturing of flight vehicles for flight within and 
beyond Earth's atmosphere. This includes aircraft both for military and civil applications as well as space launch vehicles and spacecraft.

The aerospace industry was an early adopter of carbon composites (Dorey, 1987). Military aircraft took an early lead in the development of composite materials and pioneered their use because of the extreme desire to obtain high performance in military combat aircraft (Åström, 2002). The introduction of composites in civil aircraft, however, driven by the potential for weight savings and thereby fuel savings, has taken a longer time, much due to the strict safety guidelines that are applied to civil aircraft (Åström, 2002). The quality standards used in the aerospace industry are rigorous and the introduction of new materials and manufacturing processes is preceded by extensive testing and evaluation. The demand for process control is high, and manufacturing processes must be stable with a repeatable output.

For space applications the production volumes are very low, since globally there are less than 100 space launches per year (Kyle, 2014). Within aircraft manufacturing an increased use of composite materials in civil aircraft has boosted the production volumes for composite structures. The production volumes, although continuing to increase, can only be characterized as low-tomedium production volumes. In 2013, Airbus delivered 626 aircraft while Boeing delivered 648 aircraft (Flottau, 2014). Airbus' best-selling one-aisle A320 family, which contains a substantial amount of composite material, accounted for 493 aircraft (Flottau, 2014). Boeings' 787, which contains around $50 \%$ composite material, was at the beginning of 2014 produced at a rate of 10 aircraft per month, which according to Boeing is the highest build-rate ever for a twin-aisle airplane (Boeing, 2014).

\subsection{Automation in Composite Manufacturing}

In composite manufacturing, especially in the aerospace industry, the manufacturing methods traditionally contain a large amount of manual labor (Mallick, 1997). There is a wide range of automatic and semi-automatic solutions for composite manufacturing; some of these manufacturing technologies are covered in greater detail in the theoretical foundation in Chapter 3. Manufacturing technologies like Automatic Tape Laying (ATL), Automatic Fiber Placement (AFP) and fully automated cells for Resin Transfer Molding (RTM) are found to be used for fabrication of composite aircraft structures (Grant, 2006). The manufacturing equipment for ATL and AFP are, according to Hoa (2009), associated with huge capital investments. Grant (2006) makes a comparison between automated manufacturing processes in composite 
manufacturing and metal processing for aircraft manufacturing, and concludes that there are only a limited number of automated processes available for composite manufacturing and that the equipment is very expensive. The limited variety of automated processes and the high investment costs are, according to Grant (2006), factors that limit the introduction of automation in the aerospace industry.

High investment costs call for high machine utilization. One way to achieve high utilization for low and medium production volumes is to use flexible machines that can manufacture a multitude of products. Upton (1994) characterizes this as product flexibility. In this thesis, the flexibility definition proposed by Upton (1994) is used. This definition states that:

"Flexibility is the ability to change or react with little penalty in time, effort, cost or performance" (Upton, 1994, p73).

\subsection{OFF-THE-SHELF SOLUTIONS}

In the information technology (IT) industry there is widespread use of Commercial Off-The-Shelf (COTS) solutions, sometimes simply called off-theshelf solutions. These are solutions that are developed by one product developer and sold or licensed to other product developers that use them instead of developing their own solutions from scratch. Examples of solutions in the IT industry can be software (McKinney, 1999: Potts, 1995) but also hardware, from the lowest component level all the way to complex hardware assemblies such as complete computers (Costa et al., 1997: McKinney, 1999). In many cases off-the-shelf solutions, used as sub-routines in the case of software or subparts in the case of hardware, are integrated into larger and more complex engineering projects (McKinney, 1999). According to McKinney (1999), some of the main advantages in using off-the-shelf solutions are that development costs, and also the task of testing and discovering defects in software, can be shared by many users. The use of off-the-shelf solutions can also speed up time to market when developing new products. Some disadvantages are that the offthe-shelf solution sometimes is not directly compatible with the rest of the system, and that the development of the solutions is done by another party, leading to unsecure long-term support, in some cases with features dropped from one release to another (McKinney, 1999). Both Potts (1993) and McKinney (1999) point out that in using off-the-shelf solutions when developing new products, the development methods need to be adapted to draw maximal use of the benefits offered in using off-the-shelf solutions. 
In this licentiate thesis, the term off-the-shelf solution is used for all solutions that are currently commercially available. Off-the-shelf solutions are here divided into two major categories. The technology category includes hardware that ranges from the lowest component or part level, through assemblies of components to a more complex system level. Off-the-shelf methods are broken down into the two subgroups processes and procedures. A process is viewed to be a set of procedures. An off-the-shelf method is an established way of performing a number of procedures and processes, for example a method for curing a specific type of material or for preparing the surface of a certain type of material for adhesive joining. The different levels that are covered by the term off-the-shelf solutions are illustrated in Figure 6.

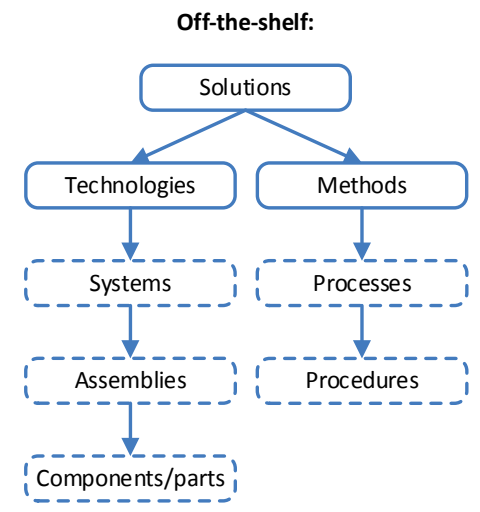

Figure 6: Levels of off-the-shelf solutions.

\subsection{RESEARCH AIM}

Studies of the industrial partners' current manufacturing systems, complemented by reviews of published material, show that there is a need for alternatives to the established technologies for automated manufacturing. Currently used automated manufacturing technologies like Automated Fiber Placement and Automated Tape Laying are associated with high investment costs, and can only be considered to be product flexible within a limited range of product geometries. Development of alternatives can be made based on different development approaches. One example is to further develop the ATL and AFP systems to achieve a higher degree of part flexibility. Another approach is to develop low-cost automated solutions instead of using complex and expensive machines that call for a high degree of utilization. These low-cost solutions might offer a high degree of product flexibility, but with low investment costs the demand for high machine utilization can be reduced. 
Therefore, the need for flexibility can be lower, which in turn can allow for less complicated solutions. One way to develop low-cost automation solutions can be to base the solutions on equipment and processes that are commercially available today, rather than to develop new solutions for the current application. This equipment and these processes, called off-the-shelf solutions, are generally developed for other types of tasks, but in this case are applied in an automated composite manufacturing context.

The aim of the research is to explore how off-the-shelf solutions developed for other uses can be implemented directly or adapted in a way that they can be used for the automation of composite product manufacturing in low and medium production volumes. Areas where off-the-shelf solutions can be directly implemented are identified, and areas where off-the-shelf solutions must be adapted to fit composite product manufacturing are recognized.

\subsection{RESEARCH QUESTIONS}

In order to guide the research process towards the research aim three research questions (RQ:s) have been formulated. The formulation of the research questions shows a logical connection to the demonstrator-centered research approach that has been utilized. The research approach is explained in Chapter 2.1.4. The first question has a natural connection to identifying the industrial challenge on a broad perspective, while the two following questions can be answered by analyzing results coming from the demonstrators. The research questions are not all-embracing, and the scope of each question should be viewed in the context of the delimitations described in the following section.

RQ 1: What types of automation are used within the industrial partners' existing manufacturing systems?

RQ 2: How can off-the-shelf solutions be used when developing automated manufacturing for composite products?

RQ 3: What challenges are associated with the use of off-the-shelf solutions for automated composite manufacturing? 
Each research question has been addressed in more than one of the appended papers. Paper IV focuses on the industrial context and is closely related to RQ1, whereas Papers I, II and III are founded on the development of demonstrators, and therefore are closer linked to RQ2 and RQ3. Table 1 shows which research question has been addressed in the appended papers, the color indicating the strength of the link between the content of the appended paper and the research question.

Table 1: The connection between the three research questions and the appended papers.

\begin{tabular}{c|c|c|c|} 
& RQ1 & RQ2 & RQ3 \\
\hline Paper I & & & \\
\hline Paper II & & & \\
\hline PaperIII & & & \\
\hline Paper IV & & & \\
\hline
\end{tabular}

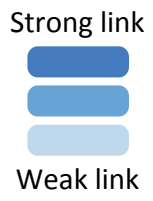

\subsection{RESEARCH DELIMITATIONS}

Composite materials are used in a wide range of applications with different performance requirements, production volumes and quality requirements. The research described in this thesis was mainly carried out in the context of aerospace applications with low-to-medium production volumes and highquality demands. The research is limited to high-performance products based on high-performance materials.

There is a wide range of manufacturing methods for manufacturing products based on composite materials. For the research included in this licentiate thesis, the focus has been on manufacturing methods for low and medium volumes that have been identified by the industrial partners to hold potential for increased automation. Therefore, the focus has been on automated layup of prepreg material, automated manufacturing of preforms for RTM and automated joining of cured composite components. ATL and AFP are considered to be mature manufacturing processes that today are highly automated and hold little potential for further automation using off-the-shelf solutions; they are therefore not included in the research scope. Other common manufacturing processes like compression molding, injection molding and filament winding are omitted due to their limited use in the aerospace sector. The major focus has been on technical solutions using off-the-shelf technologies and methods as a way of achieving low-cost automation in terms of investment costs. Flexibility is one way to make automated solutions affordable, but achieving high product flexibility has not been a primary aim. 


\subsection{DEMONSTRATORS}

It is important to distinguish between a technology demonstrator, with the purpose to demonstrate a manufacturing system, machine, device or some other type of technology, and a product demonstrator, which is a product selected to be used when testing the technology demonstrator. A product demonstrator can also be a product that is developed in an entirely new way or for a new application or purpose.

A conceptual demonstrator is an overall conceptual idea on either a technology demonstrator or a product demonstrator. The term conceptual demonstrator implies that the demonstrator has not been realized as a physical or a virtual demonstrator, but rather is a general conceptual idea. A conceptual demonstrator can be broken down into two fundaments, enabling technologies and enabling methods, as illustrated in Figure 7. The aim of a conceptual demonstrator is to highlight the enabling technologies and methods that are required to realize the concept and to place the enabling technologies and methods in a broader context.

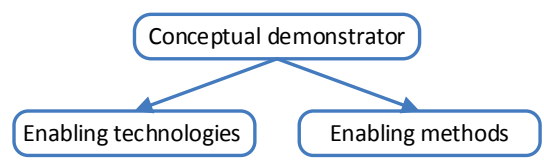

Figure 7: The two major fundaments for a conceptual demonstrator.

Enabling technologies and enabling methods can be demonstrated by the use of physical or virtual demonstrators. A realized demonstrator can, in turn, be comprised of several technical solutions. The technical solutions are only a part of a larger demonstrator that demonstrates an enabling technology, and therefore they are distinguished from the somewhat wider demonstrator term. Demonstrators that are realized, either as physical or virtual demonstrators, are used for experimentation and evaluation.

The research presented in this licentiate thesis is mainly based on work with three conceptual demonstrators, covered in greater detail in Papers I, II and III. Each of the three conceptual demonstrators is a technology demonstrator, and each deals with a concept for automated composite manufacturing for three different product demonstrators. None of the conceptual demonstrators have been fully realized, but demonstrators to investigate and experiment with several enabling technologies, and in some cases enabling methods as well, have been developed using the demonstrator-centered research approach 
presented in Chapter 2.1.4. The aim of each of the three conceptual demonstrators, as well as an overview of what enabling technologies and methods each conceptual demonstrator has dealt with, are given in Table 2. The table also shows in which of the appended papers each respective conceptual demonstrator is described in greater detail.

Table 2: The connection between the three conceptual demonstrators' aims, demonstrated enabling technologies and demonstrated enabling methods, and in which of the appended papers the detailed results of the demonstrators are published.

\begin{tabular}{|c|c|c|c|}
\hline & $\begin{array}{c}\text { Conceptual } \\
\text { Demonstrator } 1\end{array}$ & $\begin{array}{c}\text { Conceptual } \\
\text { Demonstrator } 2\end{array}$ & $\begin{array}{c}\text { Conceptual } \\
\text { Demonstrator } 3\end{array}$ \\
\hline $\begin{array}{l}\text { Conceptual } \\
\text { demonstrator aim }\end{array}$ & $\begin{array}{l}\text { Fully-automated } \\
\text { manufacturing cell } \\
\text { for cutting and layup } \\
\text { of flat laminates } \\
\text { based on prepreg } \\
\text { material }\end{array}$ & $\begin{array}{l}\text { Fully-automated } \\
\text { manufacturing cell } \\
\text { for RTM preforms } \\
\text { based on } \\
\text { unidirectional dry } \\
\text { fiber mats }\end{array}$ & $\begin{array}{l}\text { Fully-automated } \\
\text { manufacturing cell } \\
\text { for adhesive joining } \\
\text { of cured composite } \\
\text { components }\end{array}$ \\
\hline \multirow[t]{3}{*}{$\begin{array}{l}\text { Demonstrated } \\
\text { enabling } \\
\text { technologies }\end{array}$} & $\begin{array}{l}\text { Gripping of prepreg } \\
\text { plys }\end{array}$ & \multirow[t]{3}{*}{$\begin{array}{l}\text { 3D ultrasonic cutting } \\
\text { of preforms }\end{array}$} & $\begin{array}{l}\text { Gripping and } \\
\text { manipulation of } \\
\text { cured components }\end{array}$ \\
\hline & \multirow{2}{*}{$\begin{array}{l}\text { Automated removal } \\
\text { of prepreg backing } \\
\text { paper }\end{array}$} & & Adhesive dispensing \\
\hline & & & Fixture design \\
\hline $\begin{array}{l}\text { Demonstrated } \\
\text { enabling methods }\end{array}$ & $\begin{array}{l}\text { Initial separation } \\
\text { using bending }\end{array}$ & - & $\begin{array}{l}\text { Adhesive dispensing } \\
\text { methods }\end{array}$ \\
\hline Described in & Paper I & Paper II & Paper III \\
\hline
\end{tabular}




\section{ReSEARCh Methodology}

The research described within this licentiate thesis is included in the field of manufacturing engineering. The field itself is multidisciplinary and uses knowledge and tools from various other fields such as automation, industrial robotics and material science. The research herein is characterized by a high degree of collaboration with industrial partners, and the technologies used or developed exhibit a high level of technology readiness, meaning that they are close to being implemented in an ordinary manufacturing environment. 
In engineering disciplines working with technology development it is sometimes difficult do decide what is ordinary technology development, perhaps in the form of product development, and what can be considered to be research activities. The same dilemma can of course be found in many other areas as well, and is therefore widely discussed in literature within the field of research methodology. For that reason it is important to start by investigating how research differs from other activities. Trying to interpret the nature surrounding us seems to be a basic human motive, and new discoveries are a fundamental part of a civilization's development. What then is formal research, and what can be considered as ordinary, day-to-day- activities? On that question Williamson et al. (2002) state that formal research must be a process that is carried out with rigor and discipline in a highly self-conscious manner. There are numerous definitions of the terms research and research methodology. Some of them are generic and comprehensive, such as the definition used by Hernon (1991, p3-4) that states:

"Research is an inquiry process that has clearly defined parameters and has as its aim, the:

- Discovery or creation of knowledge, or theory building;

- Testing, confirmation, revision, refutation of knowledge and theory; and/or

- Investigation of a problem for local decision making."

Leedy (1997, p5) also provides a broad definition of research:

"Research is a process through which we attempt to achieve systematically and with the support of data the answer to a question, the resolution of a problem, or a greater understanding of a phenomenon."

Leedy (1997) clearly ties together research, from a broader perspective, with research methodology in denominating the process, referred to above, as research methodology. Thereby Leedy (1997) highlights the importance that the research follows a specific plan or procedure, and that research is of a cyclical, or more specifically of a helical, nature. The research methodology is, according to Leedy (1997), of major importance for the data collection as the methodology controls the study, dictates the data acquisition, arranges the data in logical relationships and guides the evaluation of the data to form a conclusion that can lead to expanded knowledge. It is important to recognize that data are ephemeral and ever-changing, and that data are always subjected to interpretation where two individuals can see different meanings in the same set 
of data (Leedy, 1997). Therefore, data should always be viewed from as many angles as possible before drawing conclusions.

Williamson et al. (2002) make a distinction between basic research and applied research, and provide the following definition of the two: Basic research (can also be called pure or fundamental research) is concerned with the deriving of new knowledge, whereas applied research is more engaged with solving specific problems in real-life situations. Generally, the applied research holds a more pragmatic view and emphasizes information that is immediately usable in the solution of actual problems. The difference between basic and applied science is not always clear. Applied, research can, for example, make contributions to fundamental knowledge and generate new theory (Williamson et al., 2002).

\subsection{RESEARCH APPROACHES AND RESEARCH METHODOLOGIES}

The terms research approach and research methodology, or simply method, are closely related and are sometimes difficult to distinguish. They are used differently by various authors of research methodology literature, and in many cases the definitions tend to overlap each other. In this thesis the two terms are also closely linked, but they are slightly distinguished in a way where the term research approach is used for the most fundamental outlook, or way of viewing, the research field. The research methodology, or method, is more focused on the way that the practical research is conducted, how experiments are performed and how data are collected and evaluated. The best example of this distinction will be shown in the case of action research, where the core of the research approach is the cyclic manner in which the research is conducted, and where in each cycle different methods can be used to generate and evaluate data. Below follows a presentation of a set of approaches or methodologies that stem from different traditions and are applied within various fields of science. The common denominator is that they are used in applied science and can be related to research within an industrial context, as well as within a general engineering discipline.

\subsubsection{ACTION RESEARCH}

According to Leedy (1997) the action research approach is a type of applied research that is concerned with finding a solution to a local problem in a local setting. Oosthuizen (2002) shares the same view as Leedy, i.e. that the approach is concerned with single situations. Furthermore, Oosthuizen (2002) points out some other typical characteristics of action research: the research is usually 
intended to bring about change at the same time as creating knowledge, and the research is done in a cyclic manner. Dick (2000), in describing the main characteristics of the research approach, also mentions that it is cyclic. Dick (2000) also notes other characteristics: action research is participative where informants are involved in the research, it mainly focuses on qualitative data, and is to a high degree a reflective method.

An illustration of the cyclic manner in which the research is performed is shown in Figure 8. Action research is an emergent process that takes place gradually, and where the outcomes of earlier cycles determine how later cycles will be carried out (Dick, 2000). This allows for gradual refinement where, in the later cycles, the interpretation of information from earlier cycles can be tested and refined (Dick, 2000).

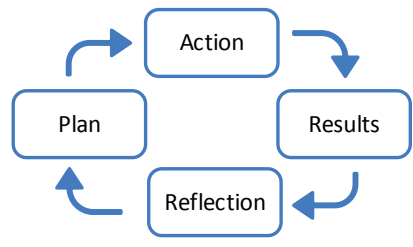

Figure 8: The action research cycle, adapted from Oosthuizen (2002).

The researcher starts with planning a cycle, and then carries out an action that gives a response. The response can be observed and treated as a result of the action. One of the most important parts of the research approach, according to Dick (2000), is the critical reflection that follows the result. The researcher, in the reflection stage, recollects and tries to make sense of what has happened, and the insights gained from the reflection can be put into use in later cycles (Dick, 2000). A new cycle is planned and, according to Oosthuizen (2002), there is no reason to use the same method or tools for the new cycle that were used for the previous cycle. The approach is largely based on letting the data determine the next step in the research process, and this iterative process can lead from a fuzzy, exploratory, beginning of a research project to a more precise ending (Dick, 1993).

Action research can be used to propose theory and to test theories, but is not considered appropriate to show general applicability of theories (Oosthuizen, 2002). According to Oosthuizen (2002), action research can be carried out in a rigorous manner and deliver reliable and valid results. To insure rigor and relevance in action research, Dick (1997) promotes the use of multiple cycles and a critical attitude where the researcher, at each cycle, tries to disconfirm the 
emerging interpretation, and at the same time critically examine the method used and refine the methods for coming cycles. Divergent data should be sought out and examined, and literature should be used as a possible source of disconfirmation (Dick, 1997).

\subsubsection{INDUSTRY AS LABORATORY}

The industry as a laboratory approach originates from the field of software engineering research, but its basic principles can be applied to more general engineering problems. The fundamental idea in the industry as a laboratory approach is that a researcher identifies problems in close cooperation with industrial projects, and creates and evaluates solutions in continuous interaction with the industrial projects (Potts, 1993). The refinement of the research takes place as incremental steps, and the researcher is continuously moving between the research and the application domains. The approach, illustrated in Figure 9, embraces the idea of continuously working with real-world problems as a way to simplify implementation of research results. This is in contrast with the more traditional view of research-then-transfer that, according to Potts (1993), often fails to address significant problems as well as fails in the implementation of research results.

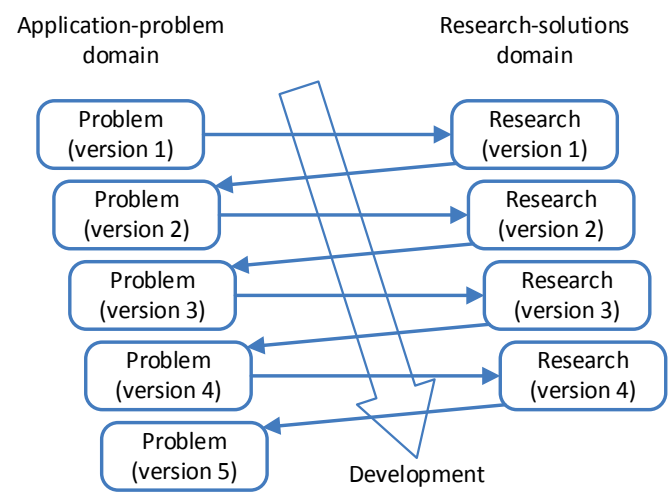

Figure 9: Industry as a laboratory, adapted from Potts (1993).

The approach can, according to Potts (1993), be viewed as a case study where a real-world project exhibits the problems of interest for the researcher and becomes a way to obtain knowledge as well as appreciate the significance of the new knowledge. The advantages in working with this approach are that the research process becomes more problem-oriented and there is less emphasis on a separate technology phase of the research project, and that interim results are directly applied throughout the research process, allowing feedback to shape 
subsequent investigations. The results from research based on the industry as a laboratory approach can be generalized to some extent, for instance from one organization to another or from a single system to a system domain, but it is unrealistic to expect generalizations for all systems or organizations (Potts, 1993).

\subsubsection{System DeVELOPMENT RESEARCH}

The system development research approach stems from information system research where the aim is to study the effective design, delivery, use and impact of information technology in organizations (Burstein, 2002). The research is often considered to be of a multidisciplinary nature, and according to Nunamaker et al. (1990) the idea of system development in the form of a research methodology fits into the category of applied science, and is suitable for instance in engineering research.

According to Burstein (2002), the approach is a way to perform research through exploration and integration of available technologies to produce an artefact, a system or a prototype. The system development methodology holds three major steps: concept development, system building and system evaluation (Burstein, 2002). Nunamaker et al. (1990) view systems development research as being formed on four separate research strategies, as shown in Figure 10 and explained in the following text.

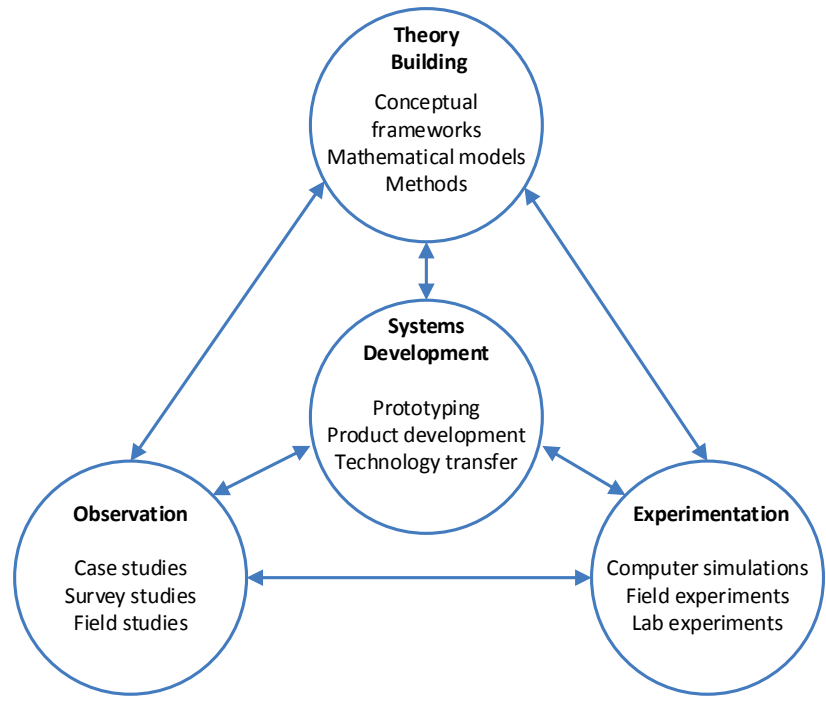

Figure 10: The four research strategies in systems development research, adapted from Nunamaker et al. (1990). 
The theory-building strategy includes the development of new ideas and construction of methods or models. The theories are mainly aimed at general system behaviors and tend to be of less practical value for the research area. Observations as a research strategy include methods for data collection like case studies, field studies and surveys. They can be used in the beginning of a project where little is known, and can be used to formulate a hypothesis that then can be tested by experiments. The experimentation strategy comprises of all types of testing and simulations as well as laboratory tests and field experiments. The aim of the experimentation is to bridge the gap between theory building and observation. Generally, the experiments are guided by theories and facilitated by the system development. The major component, the fourth research strategy mentioned by Nunamaker et al. (1990), is the system development. The system development can, according to Nunamaker et al. (1990), be divided into five stages, as illustrated in Figure 11. The five stages, presented below, can be viewed to be a more detailed description than the breakdown into three major steps, presented by Burstein (2002).

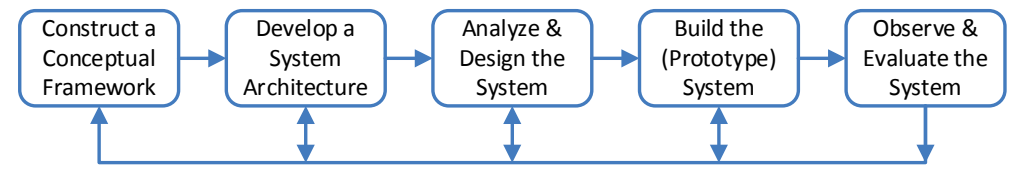

Figure 11: The five stages of systems development, adapted from Nunamaker et al. (1990).

1) The construction of a conceptual framework involves broad study of the area at hand to understand the system-building process, and study of adjacent disciplines to find alternative ideas and inspiration for the work at hand. The output of the first stage is a research question that guides the subsequent work.

2) In the development of the system architecture stage the focus is on system functions and what components can solve different sets of system functionalities. During the process the structural relationship between components is mapped. The output is a roadmap for the detailed design of the system.

3) The analyze and design phase uses the system architecture, and based on it generates design specifications that in turn are used when the system is to be implemented. The work requires detailed scientific and technical knowledge in developing a number of design solutions and evaluating them to recommend one solution for implementation. 
4) Building the system in full scale or a prototype of the system is done so the system can be tested in a real-life setting. The building itself can generate valuable knowledge about the system's advantages and disadvantages, and can lead to further development of the system.

5) When the system is built it offers the possibility for the researcher to observe and experiment with it. The evaluation of the system should be clearly linked to the research question and the framework developed in the first stage. The results can be used to formulate new theories as well as explain newly observed phenomena. The knowledge base gained during the process can also be used for further developing the system.

According to Burstein (2002), the major difference between system development as a research approach compared to conventional system development is that the research approach focuses on the concept that the system has to illustrate, and not so much the quality of the system implementation, as is the case in conventional system development. However, even if there is less emphasis on implementation quality the method can generate valuable results for the particular case, as well as contribute to expanded knowledge within the general research field (Burstein, 2002).

The system development research approach can be resource-consuming, and Nunamaker et al. (1990) argue that the approach should only be used in cases where no similar systems exist, where the effort is likely to make a significant contribution to the area and where the knowledge from the endeavor is possible to generalize for future use.

\subsubsection{Demonstrator-Centered Research Approach}

A research approach that shares some common ground with the system development research is the demonstrator-centered research approach proposed by Jonsson (2013). This research approach, schematically shown in Figure 12, rests on the threefold base of an industrial challenge, a knowledge base and a research objective. The industrial challenge is an industrial-based challenge and should be viewed as having more than a working solution and being of an everchanging nature. The knowledge base includes knowledge commonly used in the academic community, for example books, journals, reports, etc., as well as industrial knowledge such as patents, technologies, industrial partners, etc. The industrial challenge and the knowledge base are together used to form the third foundation, the research objective. In a research project this base is continuously re-examined and supports four research stages: specifications \& data, experimentation, evaluation and demonstrators. The demonstrator stage is 
central in the research approach as it is the main source of information for evaluation and experimentation.

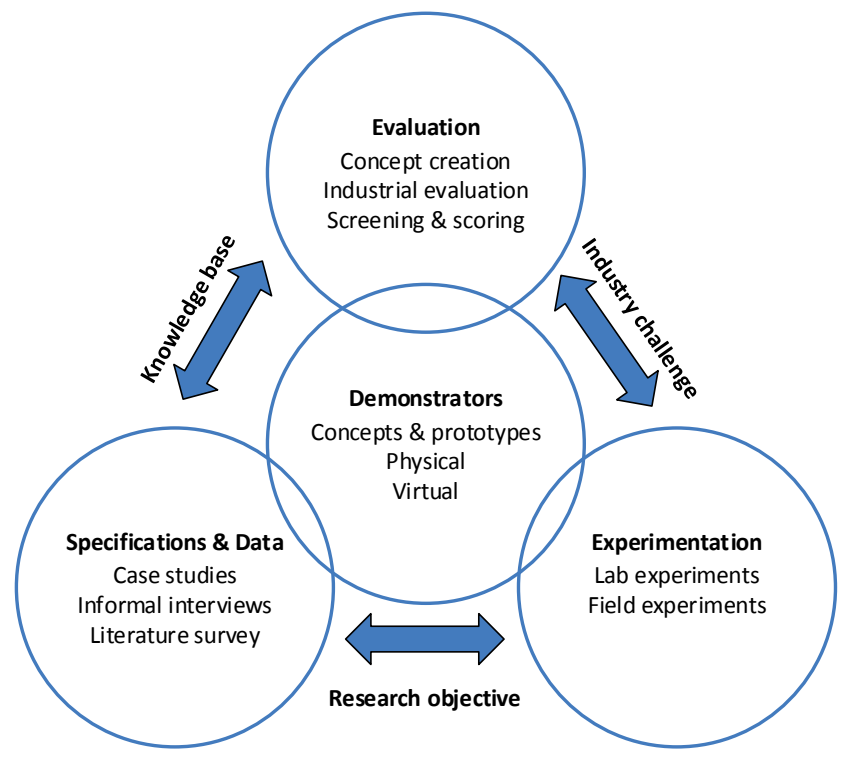

Figure 12: A demonstrator-centered research approach, adapted from Jonsson (2013).

The demonstrator can be a physical object (a machine) or a system (a network of interconnected machines), but nonphysical demonstrators such as computer models or simulations also exist. The common denominator for all demonstrators is that they fulfill a dual purpose. Most importantly, the demonstrator acts as a platform for experiments to explore and evaluate technical solutions. The demonstrator also serves as a tool for bridging the gap between the researcher and the industrial partners as it facilitates communication and collaboration.

The demonstrator is built based on specifications. The data that form the base for the specifications can be collected in a number of ways, for example case studies and interviews with industrial partners, as well as literature reviews of published material. The specifications are fed back to industry for review and updated according to the review result. Based on the specifications a technical concept is developed and refined in the evaluation phase. The technical concept is then implemented as a demonstrator and the experimentation phase begins. The whole process is iterative, and information from each step can affect the next step in the process. Information is continually flowing between the four 
research stages of specifications \& data, experimentation, evaluation and demonstrators.

\subsection{UTILIZED RESEARCH APPROACH}

The research described in this licentiate thesis can be categorized as applied research, and the utilized research approach is to a large extent based on the demonstrator-centered research approach described in Chapter 2.1.4. The practical approach is also inspired by the industry as a laboratory approach as a way of continuously bridging the gap between the research domain and the application domain. Experiments and technology development are carried out in an iterative and cyclic manner where the outcome from one experiment is analyzed and then allowed to form the future work, similar to the action research procedure. The research questions below act as a guiding roadmap through the overall research work.

RQ 1: What types of automation are used within the industrial partners' existing manufacturing systems?

RQ 2: How can off-the-shelf solutions be used when developing automated manufacturing for composite products?

RQ 3: What challenges are associated with the use of off-the-shelf solutions for automated composite manufacturing?

The research questions can be put in the context of the demonstrator-oriented research approach. The first research question (RQ1) aims to define the context in which the research is conducted. At the same time, it also provides an understanding of the industrial challenge. In working with the first research question the existing knowledge base is also mapped on a general level. The second research question (RQ2) as well as the third (RQ3) can be directly linked to the demonstrator-centered research approach's research objective. The second research question is closely connected to the demonstrator as the objective is to investigate how off-the-shelf solutions can be used; this is done by building demonstrators based on off-the-shelf solutions. The third research question is linked to the lessons learned from the experimentation and evaluation stages, and focuses on widening the knowledge base for further developments of the current demonstrator or for future demonstrators within the same field.

The research has been performed in several research projects resulting in several demonstrators, thus providing a wider understanding of the use of off-the-shelf 
solutions for automation in composite manufacturing in different contexts. Each demonstrator can be viewed as one cycle in the action research approach. It is important to note that each project is centered on one conceptual demonstrator. This conceptual demonstrator can however be comprised of a compilation of several physical or conceptual demonstrators that can illustrate an enabling technology or an enabling method. Each demonstrator can in turn be comprised of several technical solutions, which are combined in a demonstrator that is used for experimentation and evaluation. In the case of publications, each of the appended Papers I, II and III can be clearly linked to one conceptual demonstrator, although the focus of a particular publication might be on a limited area of that conceptual demonstrator. Each demonstrator results in detailed experiences and knowledge about the particular technologies or methods at hand, but it also generates more general knowledge about implementing off-the-shelf solutions in automated composite manufacturing. The experiences gained from the experimentation and evaluation of previous demonstrators are used in later demonstrators, as the knowledge base is continuously widened.

\subsection{Methods And ToOls}

In the utilized research approach, several tools and methods are used in various stages of the research. In understanding the industrial challenge, the approach has been to mainly use qualitative research designs for data collection. The research designs employed have been influenced by case studies and descriptive surveys on a general level and by field studies and both unstructured and semistructured interviews for data collection. This has provided a broad understanding of the present situation, and also revealed areas where the approach of using off-the-shelf automation as a tool to improve the current manufacturing can be used. In addition to studying the current situation by means of interviews and on-site observations of the manufacturing system, the existing descriptions of the current situation, for example in the form of work instructions and process flowcharts, have been analyzed and compared to the results from on-site observations and interviews. Much of the information collected about the current situation has become part of the industrial knowledge base and was used in the development of specifications for the demonstrators. The industrial knowledge base was also complemented with an academic knowledge base developed through literature reviews of academic publications. 
Working with the development of technical solutions for the demonstrator stage, technology reviews have been an important and frequently used approach. A technology review is herein denominated as a review of a certain technology or technical solution; it can be an investigation of the function of an individual component or machine that is considered for a technical solution, a complete system, a manufacturing process or a method. The technology review is based on material published within the academic and scientific communities in the form of journal articles, books etc., but in addition to an ordinary literature review, a technology review also draws knowledge from other types of sources. For example, commercial information about a product can be collected from product manuals and handbooks as well as from suppliers' prospects. Patents also serve as a source of information. Interviews with experts, users or manufactures of a certain technology are an interesting source of information as well. The information collected is systematically arranged and evaluated. The purpose of a technology review is, in a general case, to investigate how a particular technology can be used to solve a particular problem within the research project.

Preliminary tests to test the functionality of an interesting solution found in a technology review have complemented the theoretical review. Different solutions have been combined into concepts, and the concepts have been evaluated compared to the specifications set for the demonstrator. The evaluation has drawn upon evaluation methods such as the scoring techniques proposed by Ulrich and Eppinger (2008). Technology development and concept generation, on both the conceptual demonstrator level and on the level of enabling technologies and methods, has, in some cases, been brought forward by student projects. These projects have been continuously supervised and the project results thoroughly documented to save all the generated data.

The evaluation of demonstrators, or in some cases technical solutions intended to be a part of a demonstrator, has in many cases been conducted by means of testing. When initiating a test the final outcome was in many cases difficult to predict; therefore, the test development has been, as the example in Figure 13 shows, an iterative process. The iterative process has given an opportunity to improve how the test is carried out, and at the same time improve the evaluation methods so that the final test sequence can generate results that help in deciding future development of a technology solution or the continuous development of the demonstrator. 


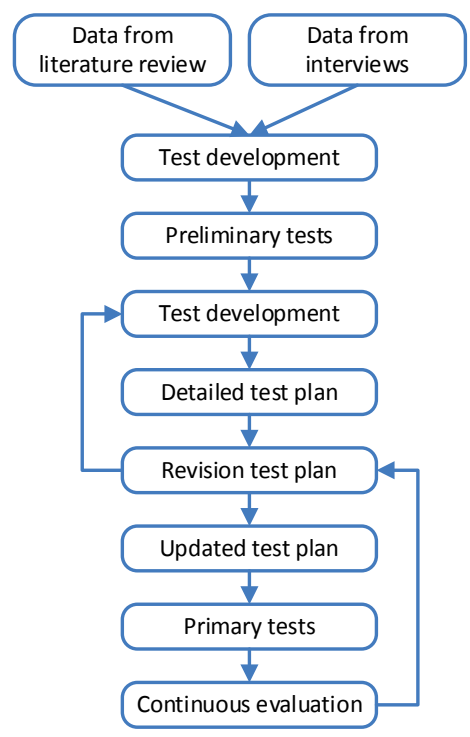

Figure 13: An example of the iterative work involved in testing and the subsequent test plan development, adapted from Paper II.

The output has in many of the projects been some sort of functioning demonstrator. The demonstrator itself and the technical solutions used in its design might only be valid in a confined context, but much of the knowledge used in developing the demonstrator can be generalized to a level where it can be used in other contexts. This is in accordance with the view of Williamson et al. (2002b) that applied research is mainly focused on solving a problem, and that the emphasis in that type of research is on information that can be immediately usable. They also highlight that within the qualitative paradigm generalization of results are not essential, and in many cases it is not possible to make generalizations at all (Williamson et al., 2002b).

\subsection{RESEARCH VALIDITY AND RELIABILITY}

According to Williamson et al. (2002b), validity is a measurement that refers to the extent to which a research instrument measures what it is designed to measure, while reliability is concerned with obtaining stabile results with replication. The work spent on understanding the industrial challenge and building the knowledge base is a way of, as far as possible, ensuring that the demonstrator actually gives answers that are useful in trying to fulfill the research objective. This is one way to make sure that the demonstrator, which in this case is considered to be an instrument generating knowledge, is valid. The reliability aspects are somewhat harder to address. In the current case of applied 
research in an ever-changing industrial environment, replication of the full context must be considered to be impossible. However, detailed data and experiment descriptions and results are managed in a way that allows for renewed evaluations and interpretations, even though the surrounding context has changed.

The data analysis has to a large extent consisted of two approaches presented by Leedy (1997): interpretational analysis, where data is examined to find patterns that can explain an observed phenomenon, and reflective analysis, where the researcher's intuition and judgment is used to portray and evaluate a phenomenon.

Leedy (1997), in describing methods for increased validity in qualitative research designs, is refereeing to Gall et al. (1996), who suggest several strategies to achieve trustworthiness in a qualitative study. Some of the strategies that Leedy (1997) attributes to Gall et al. (1996) are member checking and triangulation. Member checking is the process in which the participants involved in a research project are allowed to review data and interpretations, looking at accuracy and completeness. The results of the review are fed back and used to correct and improve the quality of the material. Triangulation is the use of multiple data collection methods and analysis methods to check for validity in findings. The credibility of an interpretation is enhanced if similarities between different collection and analysis methods are noted (Leedy, 1997 referring to Gall et al., 1996). In the work involving interviews and observations to define the industrial challenge and build the industrial knowledge base, the strategy of member checking has in some cases been utilized, and interview subjects have been asked to read condensed versions of the interviews as well as to comment on the results from the interviews. Triangulation has been achieved by comparing information collected through interviews, observations and data available in the form of work instructions, etc. Triangulation has also been achieved by comparing knowledge generated by several different demonstrators.

In the description of how to carry out action research with rigor, Dick (1997) promotes the use of short and multiple cycles and an attitude, on behalf of the researcher, where new information is constantly used to try to disapprove interpretations form earlier cycles. This approach of short, multiple cycles has especially been applied to test development, and the critical approach trying to disprove earlier interpretations has permeated the whole research process. 


\subsection{RESEARCH ENVIRONMENT AND RESEARCH PROJECTS}

The research described in this licentiate thesis has been conducted in the context of several research projects. All of the research projects have in some way dealt with automated composite manufacturing, although with somewhat different aims and in very varying contexts. The chronological order of the research projects is illustrated in Figure 14, and a general description of each project is provided below.

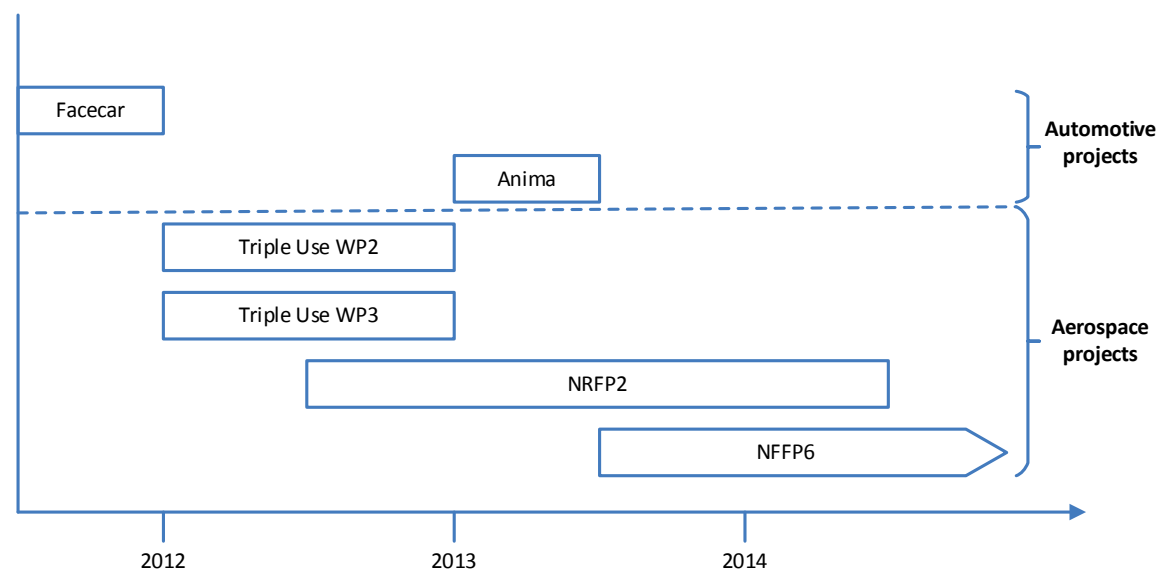

Figure 14: A time line showing the research projects.

The research projects can be divided into two groups. The first group includes Facecar and Anima, and deals with automotive manufacturing where the production volumes are high but the use of composite materials, today, is limited. There is a strong focus on high-volume production and low cost. The second group consists of two separate work packages of the Triple Use project as well as the NRFP2 and NFFP6 projects. In this group, all the project partners are companies within the aerospace sector. The sector is characterized by a demand for high performance and high quality, a long use of composite materials and manufacturing techniques which are in many cases manual. The manufacturing volumes can be described as low to medium, much lower than in automotive manufacturing. The automotive projects have served as a learning platform for composite manufacturing in general and for production engineering thinking for high-volume production, which is an important input to the aerospace-associated projects. The projects within the aerospace area have offered in-depth technology studies and development of new technology based on off-the-shelf equipment from other lines of business. Based on the low production volumes the concept of automation using off-the-shelf equipment is 
suitable. The appended articles and the results enclosed herein mainly stem from the research projects performed with industrial partners from the aerospace industry.

\subsubsection{FACECAR}

The Flexible assembly for Considerable Environmental improvements of CARs (Facecar) project ran from 2009 to 2011, and involved three large vehicle manufacturers and some of their suppliers as well as research organizations and universities. The project was funded by Vinnova's Strategic Vehicle Research and Innovation program. The overall purpose of the project was to investigate and develop manufacturing processes suitable for the manufacturing of environmentally friendly vehicles. The main focus was on the final assembly of cars. Within the project a small investigation of manufacturing methods for manufacturing structural parts of composite materials was conducted. This investigation served as a learning opportunity in the field of composite materials and manufacturing processes as well as an introduction to the Swedish automotive industry.

\subsubsection{ANIMA}

Assembly of future vehicles in new lightweight materials (Anima) was a minor project involving a Swedish automotive manufacturer as project partner. The project was funded by Vinnova's Strategic Vehicle Research and Innovation program. The aim was to investigate what types of manufacturing processes and systems will be needed for the manufacturing of future cars with a high content of lightweight materials. A state-of-the art analysis of technologies used for manufacturing cars with a high degree of composite materials was undertaken. Special attention was also given to methods for joining lightweight materials.

\subsubsection{TRIPLE USE}

The Rapid and low-cost manufacturing of high-performance composite components (Triple Use) project is scheduled to run from 2011 to 2014 and is funded by Vinnova. The project is a collaboration between three different user groups of composite materials, civil aircraft, and military aircraft and automobiles, thereby the name Triple Use. The project is set up in separate Work Packages (WP), each WP with a unique aim. The work included herein stems from two separate work packages that are so different that they are treated as separate projects below. The full project is divided into three separate phases, and the work described below was carried out during 2012 in the first phase of the project. During the first two stages the project is aimed at developing methods and technologies that will be implemented in the final stage, where a 
set of demonstrators is planned to be built. During the first two stages smaller demonstrators can be constructed as proof of a particular concept.

\section{TRIPLE USE WORK PACKAGE 2 (WP2)}

Within the second work package the first phase of the Triple Use project was focused on civil aviation, and the aim was to develop an automated manufacturing system, or cell, for the manufacturing of products by means of resin transfer molding. The work included in the thesis concerned threedimensional ultrasonic cutting of dry preforms, and was based both on a survey of published material within the field of ultrasonic cutting and physical tests of standard cutting equipment mounted on an ordinary industrial robot.

\section{TRIPLE USE WORK PACKAGE 3 (WP3)}

Within the third work package the first phase of the Triple Use project was aimed at automated manufacturing of a component for civil aviation. The product was prepregbased and produced in what within the aerospace industry could be considered medium to high production volumes. One subpart of this scope was the handling of the uncured prepreg in an automated pick-and-place process, and especially the automated handling of the protective backing paper that covers the prepreg. Based on a broad literature review in the field of gripping technology a concept for prepreg handling and backing paper removal was developed and tested.

\subsubsection{NRFP2}

Automatic manufacturing of composite structures (a part of the NRFP2 research program and therefore denominated NRFP2) was a two-year project that ran from 2012 to 2014. The project partners involved were a company that manufactures composite structures for space applications and a research institute. The project was funded by the Swedish national space board's NRFP program. The main focus for the project was the development of a new product design that allowed for a novel manufacturing process that was developed in parallel with the product. A concept for an automated manufacturing cell was developed and evaluated by means of technology reviews based on published information, digital simulations and physical tests.

\subsubsection{NFFP6}

Automation for composite manufacturing (a part of the NFFP6 research program and therefore denominated NFFP6) is a project that draws on the knowledge developed during the Triple Use project. The project partners are a large company within the aerospace industry and a research institute. The 
project is funded by Vinnova through the National Aviation Engineering Research Program. The main focus is to identify manufacturing processes where automation can contribute to competitive manufacturing, develop technology for automating processes that today are manual, and by the use of demonstrators show proof of concept. 


\section{THEORETICAL FoundATION}

Within the theoretical foundation a basic introduction to composite materials and common methods for manufacturing products based on composite materials is given. The section also covers some basic theories concerning automation of manufacturing processes. It also provides descriptive presentations of adhesive joining, gripping technologies and ultrasonic cutting, three technologies that are important in the development of the conceptual demonstrators presented in the result chapter. 


\subsection{COMPOSITE MATERIALS AND THEIR CONSTITUENTS}

In the introduction the term composite material was defined and narrowed down to Carbon Fiber Reinforced Plastic (CFRP). Composite materials, in the general case, contain two main constituents: reinforcement and matrix. The reinforcement gives the material its strength while the matrix holds the reinforcement in place, protecting the fibers from the surrounding environment and acting as a path for stress transfer in-between fibers. The matrix has a major influence over the processing characteristics of a composite, and thus a great influence on the manufacturing of a composite (Mallick, 1997). In the case of polymer matrixes there are two main groups of polymers, thermosets and thermoplastics. The two matrix groups differ in general material properties and also in how they can be used in the manufacturing of composite materials. The thermoplastics are usually heated to a melting temperature, formed to a product and then cooled to solidify. Thermosets are often comprised of two or more substances that are mixed prior to use. The mixing process triggers a curing process, and the material has to be used within a limited time after mixing. For the reinforcement there are two important aspects to consider: the fiber material and the reinforcement type, or arrangement. Common fiber materials are carbon, glass, aramid and boron. Fiber diameters are generally in the range of 5$40 \mu \mathrm{m}$, although boron fibers have diameters of around $140 \mu \mathrm{m}$ (Mallick, 1997). The fibers can be either continuous or chopped to smaller sizes and arranged with oriented directions or in random patterns. Continuous fibers can be either straight or crimped, as in the case of woven reinforcement.

In some manufacturing methods, like resin transfer molding (see Chapter 3.2.1), the fibrous reinforcement arrangement is infused with liquid matrix in the tool where the final product is shaped. The two major constituents first come together to form the composite material at the same time as the part, made out of the composite material, is manufactured. This is a common approach to manufacturing parts from composite materials. There are, however, some alternatives to this approach, one important exception being the use of prepregs. A prepreg consists of a fiber arrangement that is pre-impregnated with a polymer matrix. The impregnation of the fibers is done in a separate process, and the prepreg can be considered to be a raw material in the next manufacturing step where products are manufactured using pre-impregnated fibers. In the case of a thermoset matrix the polymer in the prepreg is semicured to what is called a B-stage, and to prevent full curing the material is stored in temperatures below $-18^{\circ} \mathrm{C}$ ( $\AA$ ström, 1997). Prepregs are usually used in highcost and high-performance applications because they can offer high and uniform 
material properties due to the highly controlled impregnation process (Åström, 1997). The material type, however, is associated with high material cost.

\subsection{Manufacturing Methods}

For almost all manufacturing methods used to manufacture parts based on composite material, the material properties for the final product are greatly affected by the manufacturing process itself. In most cases it is justified to talk about manufacturing processes that produce the final material at the same time as the product (Balasubramanian, 2014; Åström, 1997). The term uncured material is commonly used to denominate a composite material that has not been fully processed and therefore has not received its final properties. For manufacturing parts made from composite materials there is a great variety of manufacturing methods to choose from. Different manufacturing methods utilize the materials in different forms; two examples of manufacturing methods commonly used in aerospace applications are shown below.

\subsubsection{Resin TRANSFER MOlding (RTM)}

In Conceptual Demonstrator 2 the main aim is a fully-automated manufacturing cell for preforms for resin transfer molding. In RTM the fibrous reinforcement is impregnated by a polymer matrix, also called resin, in the manufacturing step where the product shape is created. Fibrous reinforcement is put into a mold tool with two rigid tool halves, the mold is closed and a clamping pressure is applied on the mold. In some cases, a vacuum is drawn in the tool before then liquid polymer matrix is injected into the mold cavity (Karlsson \& Åström, 1997). Injection pressures are usually in the range of 1 to 10 bars (Gascons et al., 2012). The mold is closed until the resin has cured and then the tool is opened and the part is removed. Heat can be applied to the molding tool to shorten the curing time in the mold (Gascons et al., 2012). The mold can also be heated during the impregnation stage to lower the resin viscosity and thus facilitate impregnation (Karlsson \& Åström, 1997). The separate steps in RTM manufacturing, including the preforming process, are illustrated in Figure 15. 


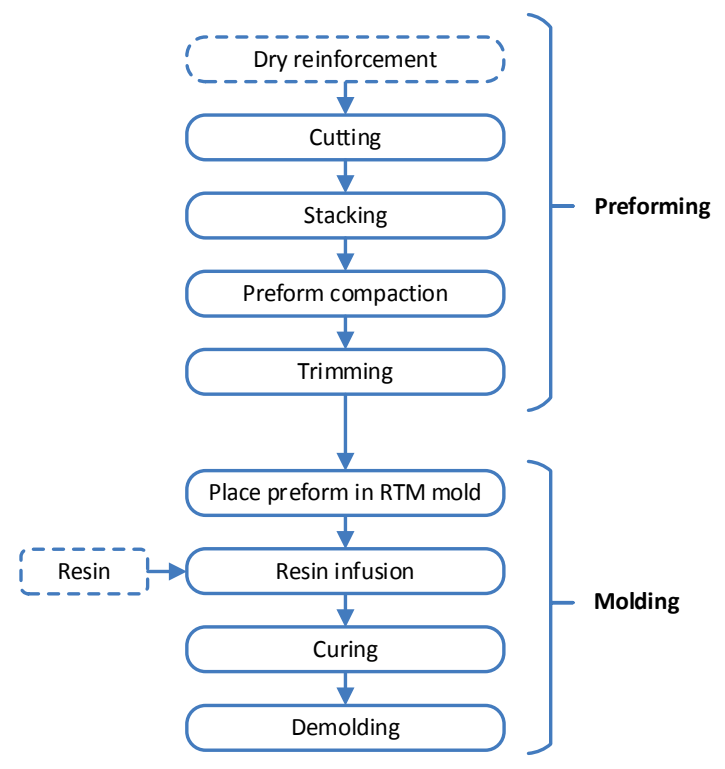

Figure 15: The manufacturing process of RTM molding including preform manufacturing, adapted from Paper II.

\section{PREFORMING}

The fibrous reinforcement can either be built up by manually stacking layers of fiber until the correct thickness is achieved in the mold, for example in the form of unidirectional or woven fabrics, or all the reinforcement can be prepared in a separate preforming process and put into the molding tool as one unit (Karlsson \& Åström, 1997). A preform is an arrangement of dry fibers bounded together to a preform that is rigid enough to be handled in subsequent operations (Owen et al., 1990). A preform can, in addition to the dry fibers, include inserts, fasteners and core materials (Owen et al., 1990). A common way to manufacture preforms is the cut-and-paste method, where sheets of a fiber reinforcement fabric are cut into simple pieces that are bound together to a preform by either adhesive bonding or stitching (Hoa, 2009). A variant of this method is thermoforming, where reinforcement that is coated with thermoplastic binder is used. Sheets of reinforcement fabric are cut and stacked in a molding tool. The tool is closed to compact the stacked fabric and heated to melt the binder material, locking the fibers in place (Hoa, 2009). The resin flow in a RTM process is affected by the preform permeability which, in turn, is dependent on the fiber type and the fiber packing (Balasubramanian, 2014). A high level of preform compaction affects the preform permeability and can result in a slow resin injection process. The preform has a limited lifetime after 
the thermoforming process as it slowly starts returning to the thickness before compaction (Hoa, 2009). To reach a good result in the infusion process it is important that the preform fits well in the molding tool (Hoa, 2009). Therefore it might be necessary with a trimming operation to cut the preform to its final shape.

A separate preforming process allows for higher mold utilization and enables the entire manufacturing process to be highly automated, and thereby suitable for high production volumes (Karlsson \& Åström, 1997). The use of preforms can also reduce the quality of the final product as well as part-to-part variations (Hoa, 2009). According to Gascons et al. (2012), further developments of RTM manufacturing is inhibited by the lack of rational preforming methods and long cycle times for the infusion process.

\subsubsection{PREPREg LAYUP}

A common way to manufacture products from prepreg is by means of manual prepreg layup. The method is highly flexible and can yield high-quality products (Karlsson \& Åström, 1997). Cutting and layup can account for $40-60 \%$ of the manufacturing costs of a part, depending on part size and complexity (Campbell, 2004).

Prepreg material is taken out from the freezer storage in advance of the cutting process to make sure that the material reaches room temperature before the wrapping protecting the material is removed (Campbell, 2004). This reduces the risk of condensation forming on the material. The material is usually handled on rolls that are up to two meters wide. In the cutting process the prepreg material is cut into smaller shapes, called plys. The cutting can be done manually but is usually made using an automated cutting machine, using either reciprocating knifes or ultrasonic knives to cut the material (Campbell, 2004). In the cutting process the plys can be labeled and they are usually sorted into kits to prepare for the layup operation. The layup is usually made by placing the plys in or on an open mold with the product shape, as shown in Figure 16. 


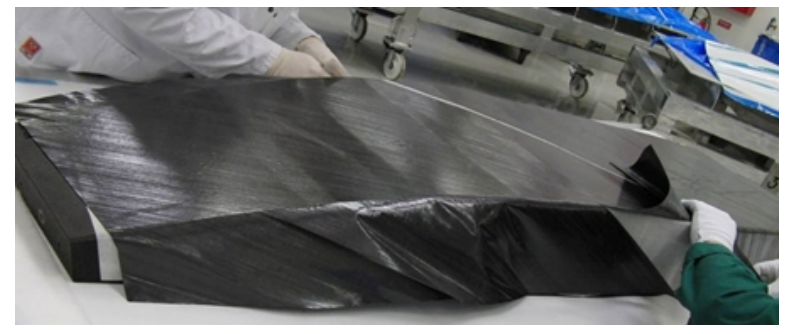

Figure 16: Photo showing manual layup of prepreg, courtesy of SAAB Aerostructures.

The plys are placed one at the time, and the operator makes sure that they have the desired orientation, that there are no bubbles or buckling, and that no foreign objects like protective backing paper are enclosed (Karlsson \& Åström, 1997). Layup of prepreg over three-dimensional surfaces, especially double-curved surfaces, can prove to be a difficult operation as tearing and wrinkling of the prepreg material can be encountered (Bader \& Lekakou, 1997). In the layup stage, several plys are stacked on top of each other in several layers to achieve the desired thickness. After a few layers of plys the layup should be debulked, a process where the material placed in the tool is covered with a plastic film and a vacuum is drawn under the plastic film and held for a few minutes (Campbell, 2004).

The debulking helps to compact the layup and remove entrapped air that can cause porosities and thereby reduce the performance of the final part. The debulking is followed by a new layup of a few layers and a subsequent debulking until the final thickness is reached. After the final plys have been placed the layup is prepared for curing in a process called cure assembly. The prepreg is covered with several layers of different types of functional materials and sealed off by a plastic film, and a vacuum is drawn under the plastic film (Karlsson \& Åström, 1997). The layers of functional materials are, for example, distributing the vacuum under the plastic film and helping the resin to flow easier during the curing cycle (Karlsson \& Åström, 1997).

Prepreg materials are usually cured in autoclaves at a controlled temperature and pressure (Gascons et al., 2012). In many cases the manufacturing of a cured composite product is followed by some sort of machining operation, for example trimming of edges or drilling of holes. An example of the process steps in manual prepreg layup is illustrated in Figure 17. 


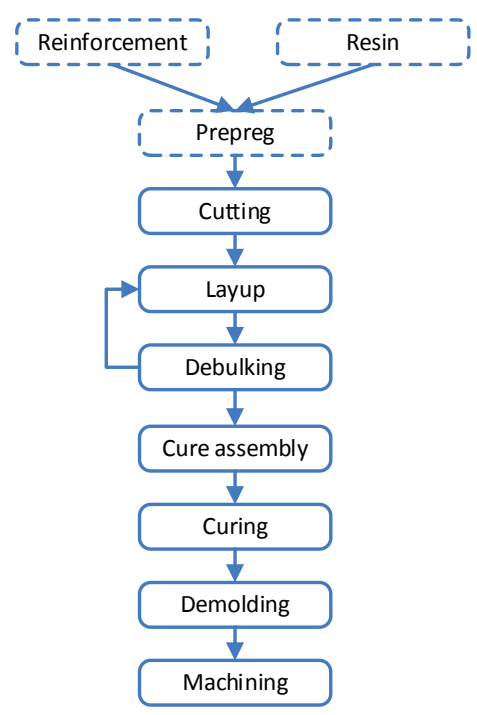

Figure 17: The manufacturing process for prepreg layup in a product shaping mold.

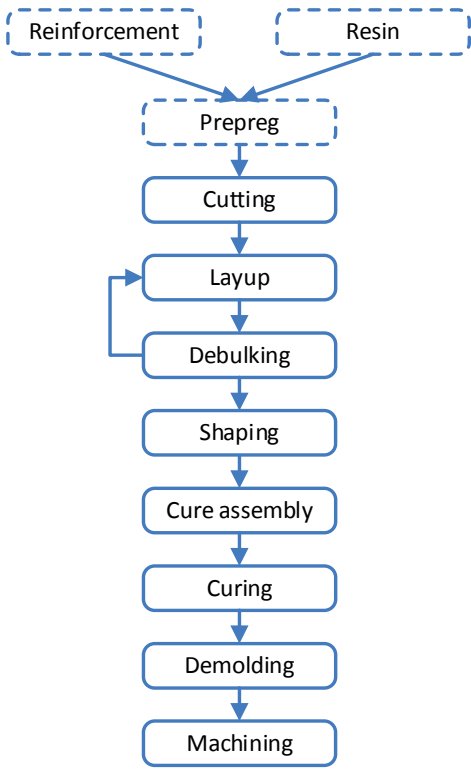

Figure 18: The manufacturing process for prepreg layup with a separate shaping process.

\section{SHAPING OF PREPREG LAMINATES}

An alternative approach to directly placing the prepreg in a mold with the same shape as the final product is a two-step solution, illustrated in Figure 18, where the prepreg is first laid up to form a plane laminate. After the completed layup the laminate is shaped in a separate shaping process, shown in Figure 19. In this shaping process, usually called vacuum forming, the laminate is placed on the shaping tool and covered by a protective film and a rubber membrane (Campbell, 2004). A vacuum is drawn under the membrane, forcing the laminate to assume the contour of the shaping tool, and the vacuum is kept in place for a few minutes to allow for the material to stabilize. Heat can be added to facilitate the forming (Campbell, 2004). The two-stage layup and shape approach can simplify the layup process, and in many cases allow for automated layup methods to be used. The shaping process, however, limits the type of product geometries that can be manufactured, and complex geometries cannot be shaped. 

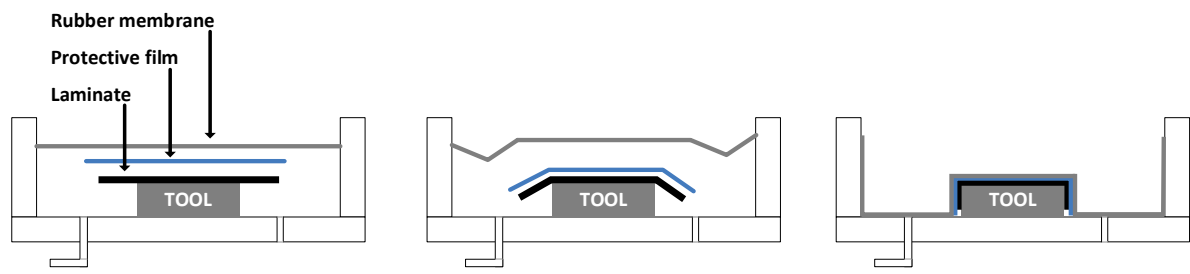

Figure 19: Illustration of vacuum forming adapted from Campbell (2004).

\section{Automated Prepreg LAYUP USing ATL AND AFP}

Manual prepreg layup is labor-intensive (Karlsson \& Åström, 1997), and automated layup methods have been developed in an effort to move towards less labor-intensive manufacturing. The two most common automated manufacturing processes are Automatic Tape Laying (ATL) and Automatic Fiber Placement (AFP). In both processes, an automated machine deposits prepreg material onto a flat surface or a contoured mold. ATL machines handle prepreg tape with a width of 75-300 mm, laying one width at a time, while AFP machines, utilizing material called tows with a width of 3.2-12.7 mm, place several tows at the same time (Lukaszewicz et al.,2012). Each tow is controlled individually in an AFP system, and therefore it is possible to manufacture more complex parts with automated fiber placement compared to automatic tape laying. The ATL, however, generally generate higher layup productivity since they are used to manufacture parts with simpler geometries (Lukaszewicz et al., 2012). In both systems the material is compacted by a roller when it is deposited on the mold, thereby avoiding the debulking necessary in manual layup (Campbell, 2004).

In general, the ATL machines are larger and heavier than the AFP systems that for example can be placed on standard robots (Coriolis Composites). An example of a gantry-mounted ATL system is shown in Figure 20, while Figure 21 shows a close-up of the tape-laying head, which can handle $300 \mathrm{~mm}$ wide prepreg. Both types of machines require a huge investment cost. The layup with ATL or AFP can be followed by a forming operation, and then the same cure assembly and cure processes as used for manual layup apply. 


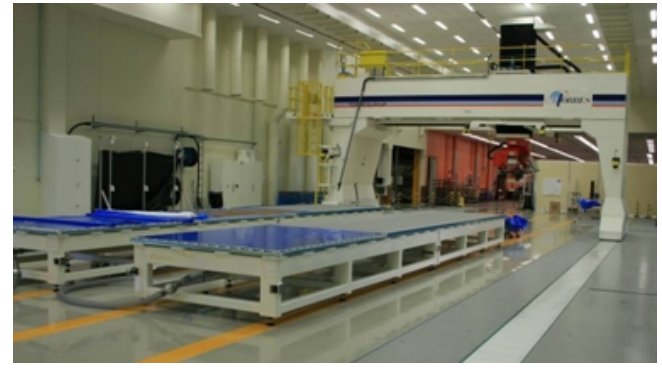

Figure 20: Picture showing a gantry-mounted ATL machine, courtesy of SAAB Aerostructures.

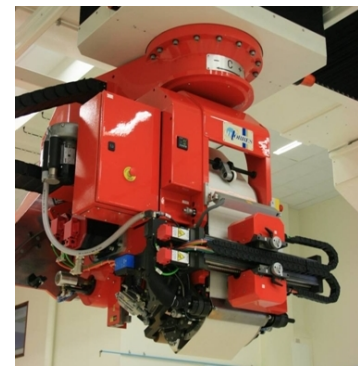

Figure 21: Close-up picture of an ATL head, courtesy of SAAB Aerostructures.

\section{Automated Prepreg Layup using Pick-AND-Place ConcePts}

Automated manufacturing using ATL and AFP technologies implies the use of specialized machines that require high capital investments. Another approach to automating the manufacturing of products using prepreg materials can be broadly categorized as pick-and-place concepts. In pick-and-place concepts offthe-shelf components and technologies are, to a high degree, used to build systems that usually focus on picking material from some sort of cutting machine and placing it in a mold or on a flat surface. There are several examples of pick-and-place systems for prepreg (Buckingham \& Newell, 1996; Newell et al., 1996; Ward et al., 2013), but the approach is also very common in handling dry fibers, for instance those to be used in preform manufacturing (Angerer et al., 2010; Brecher et al., 2013; Reinhart \& Straßer, 2011). According to Ward et al. (2012), several pick-and-place concepts have been attempted but with limited impact, and as a result the commercially-available automation equipment for composite manufacturing is mainly limited to ATL and AFP. The aim for Conceptual Demonstrator 1 is a fully-automated manufacturing cell for cutting and layup of laminates, and handling the prepreg material using a pick-andplace concept is an important part of the conceptual demonstrator.

\section{EfFect of Prepreg Material Properties on Automated Handling} When handling prepreg materials in the way that is done in a pick-and-place concept there are two issues that are important to consider: the rigidity of the fiber arrangement and the tack (Buckingham \& Newell, 1996). The rigidity of the fiber arrangement concerns how well the prepreg holds together while being handled. Prepregs with all the fiber in one direction, i.e. unidirectional (UD) materials, are sensitive to handling damage and the fibers can easily separate, since the material is strong in the fiber direction but in between the fibers there is only matrix binding them together, and thereby the material is weak in the 
direction across the fiber direction. Most prepreg materials are protected by either a protective paper or plastic film on one or both sides when they are delivered from the impregnation process. Figure 22 shows a prepreg protected by a stiff backing paper on one side and a blue plastic film on the other side. The protective paper can be kept in an automated handling process as it can improve material rigidity; keeping the protective paper also reduces the risk of material contamination in the manufacturing process (Buckingham \& Newell, 1996). Tack is usually defined as the ability of two prepreg plies to adhere to each other (Putnam, 1995), and can be explained simply as the stickiness of the prepreg material. The tack is dependent on the matrix and the fibers, as well as processing and environmental conditions such as temperature and humidity (Putnam, 1995). One way to alter the tack level of a material is to alter the temperature; it is, however, important to note that different prepreg materials will respond differently to changes in temperature (Crossley et al., 2012).

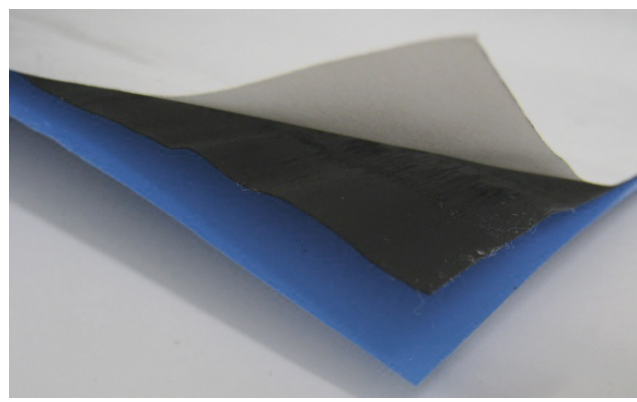

Figure 22: Prepreg with white backing paper and blue protective plastic.

\subsection{JOINING OF CURED MATERIALS}

The two most common joining methods for cured composite materials are mechanical joining, for example using bolts or rivets, and adhesive joining, where a chemical bond binds the two parts to be joined (Åström, 1997). Adhesive joining can, compared to mechanical joining, be both more cost efficient for production as well as more weight efficient (Åström, 1997). The third conceptual demonstrator focuses on an automated manufacturing cell for adhesive joining of cured composite components.

In adhesive joining, the surface of the two adherends must be thoroughly cleaned to make sure that all contaminants, which can reduce the strength of the bond, are removed (Crossley et al., 2013). For composite materials this is especially important because there is generally a wide range of contaminants to be found on the material surface due to previous processing steps (Wingfield, 
1993). In addition to removing contaminants, the surface can also be treated to allow for a stronger bond to form (Ebnesajjad, 2008; Wingfield, 1993). Surface treatment modifies the chemistry or morphology of the surface, without affecting the bulk properties of the material, to enhance the bonding (Wingfield, 1993). A number of different methods for surface cleaning and surface treatment have been developed; some of them are listed in Table 3.

Table 3: Methods for surface cleaning or surface preparation, divided into four categories based on their main principles as presented in Paper III.

\begin{tabular}{|c|c|c|c|}
\hline Mechanical & Energetic & Chemical & Bulk \\
\hline Alumina gritblast & Corona discharge & Solvent cleaning & Additives \\
\hline Cryoblast & Plasma & Detergent wash & Blending \\
\hline Sodablast & Flame & Acid etch & Recrystallization \\
\hline Peel ply & Excimic laser & Primer & \multicolumn{1}{|c}{} \\
\cline { 1 - 3 } Silicon carbide abrasion & \multicolumn{3}{|l}{}
\end{tabular}

There is no single method that works on all materials and can remove all contaminants. Which method to use is determined based on the adherend material and the adhesive at hand, as well as the intended application. General recommendations are in many cases available from the adhesive suppliers (Henkel Corporation). However, testing is needed to make sure that a cleaning and surface preparation method is suitable for any given case (Ebnesajjad, 2008; Wingfield, 1993). Some of the methods used for cleaning and surface preparation, such as corona discharge, can be rather simply integrated in an automated manufacturing cell while others, like detergent or solvent washing, are much less adapted for automated operations.

In addition to the surface preparations, correct preparation and application of the adhesive is also important. Adhesives used for advanced applications are usually comprised of two constituents that must be accurately mixed, the adhesive must be applied within a specified time after mixing, and the adhesive thickness that is applied must be correct (Crossley et al., 2013). There are numerous examples of automated systems for adhesive mixing and application (Henkel, 2008; OK International). For large-scale production, this type of equipment for adhesive dispensing is necessary to achieve an efficient manufacturing process (Adams \& Comyn, 2000). Failures in adhesive joints can generally be attributed to either poor surface preparation or incorrect adhesive preparation (Crossley et al., 2013). 
While the adhesive crosslink, cure, the adherends must be firmly held in position. This is usually done with the use of specialized bonding fixtures (Åström, 1997) to ensure geometric correctness of the joint. The fixtures generally have to be adapted to or developed especially for a particular product.

\subsection{MANUfaCturing Systems AND AUtOMATION}

In this thesis the term manufacturing system is used in accordance with a definition proposed by Groover (2008, p102):

"A manufacturing system is ... a collection of integrated equipment designed for some special mission, such as machining a defined part family or assembling a certain product. Manufacturing systems also include people."

In manufacturing as a general field there is a long-term trend to substitute manual labor with the use of automated machines (Groover, 2008). Several somewhat different definitions of automated manufacturing exist. In this thesis, a general definition inspired by Groover (2008) is used: An automated manufacturing system performs one, or several, operations, for example, processing, material handling, assembly and/or inspection on a physical product. This is done using a lower degree of human participation compared to the corresponding manual process. Automated manufacturing does not have to be fully automated; semi-automated systems where humans and machines work together are common (Groover, 2008).

There can be several reasons for automating a manufacturing system. According to Groover (2008), some common reasons for automating are improved labor productivity, reduced labor cost, reduced manufacturing lead time and improved product quality. There are also some situations where manual labor is preferred over automated solutions, for example when a task is technologically too complicated to automate, in the case of short product lifecycles, or when there is a demand for highly customized products (Groover, 2008). Automation can be implemented at different levels of manufacturing, from the lowest and most basic device level all the way to the most extensive enterprise level. All the levels in the automation hierarchy are illustrated in Table 4. 
Table 4: Levels of automation, modified from Groover (2008).

\begin{tabular}{|l|l|}
\hline Level of Automation & Description/Examples \\
\hline Enterprise level & Corporate information systems \\
\hline Plant level & Production system \\
\hline Cell or system level & Manufacturing system - groups of machines \\
\hline Machine level & Individual machines \\
\hline Device level & Sensors, actuators, other hardware elements \\
\hline
\end{tabular}

For composite manufacturing the main advantage with the use of automation is, according to Newell et al. (1996), the possibility to increase overall quality and uniform consistency for the products. The layup and consolidation processes benefit significantly from a more repeatable process compared to manual layup (Newell et al., 1996). Another important driver for automation in composite manufacturing is the need to manufacture products in more cost-efficient ways, using less manual labor. As previously mentioned, the two main technologies today for automated composite manufacturing using prepreg materials are automatic tape laying and automated fiber placement (Lukaszewicz et al., 2012). Apart from the two dominant technologies for automated manufacturing using prepreg materials, other low-cost concepts have been developed, for example pick-and-place, but they are not as well established. The main reason for the lack of automation solutions using a pick-and-place concept is, according to Newell et al. (1996), the problems associated with automated handling of flexible, fragile and sticky materials that are usually a major constituent in composite materials.

\subsection{GRIPPING TECHNOLOGIES}

One of the most common requirements in automated composite manufacturing using a pick-and-place of prepreg is to pick up a prepreg ply from a cutting table, and transfer it to either storage or a mold tool, where it is put down in a controlled manner (Newell et al., 1996). The same handling operation is also valid in other manufacturing methods, for example the manufacturing of preforms for RTM (Brecher et al., 2013) and for the handling of cured composite material in the case of automating an adhesive joining process. To achieve the pickup of a material there are numerous technologies, based on various physical principles, to choose from. These technologies are summarized in Figure 23 and their basic principles, as well as their applicability in automated composite manufacturing, are discussed below. 


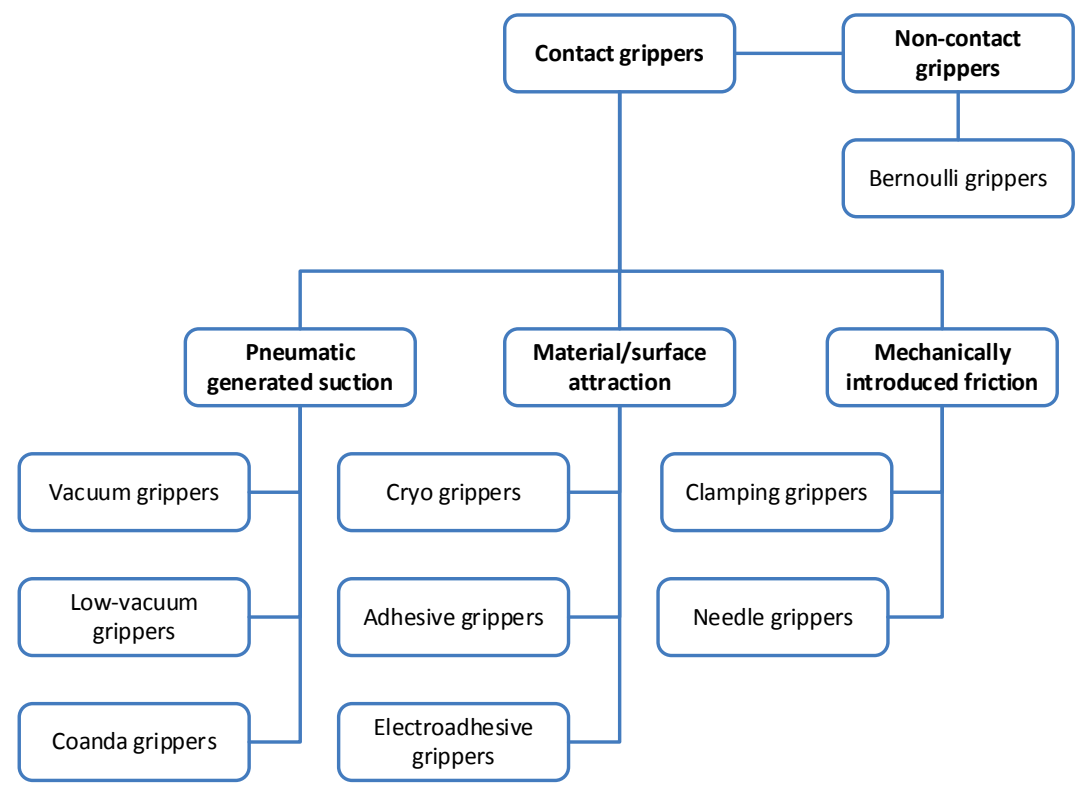

Figure 23: Summary of gripping technologies, as presented in Paper I.

There are two main principles for gripping technologies: contact grippers, where the gripper is in physical contact with the material it should grip, and noncontact grippers, where the material never touches the gripper. An example of non-contact grippers are Bernoulli grippers, which utilize the underpressure created when a high-speed airflow is directed between the material to be lifted and the gripper (Dini et al., 2009). The material floats just below the gripper surface without any physical contact between them (Dini et al., 2009). One advantage is the possibility to lift a material without physical contact, while disadvantages are that the material is deformed by the air flow and the material does not retain its position and orientation since it floats freely under the gripper (Ozcelik et al., 2003).

Vacuum grippers are commonly used for automated material handling of a wide array of materials, and there is a vast amount of available gripper designs and materials to select from. Ordinary vacuum systems are based on creating a high underpressure with low air flows, but there are alternatives, called low-vacuum systems, that generate a lower underpressure but compensate with high airflows to maintain the attraction force to the gripper surface (Lien \& Davis, 2008). For the ordinary vacuum systems, some disadvantages are that soft and highlyflexible materials can be deformed as they are sucked into the vacuum cup, and that very porous materials leak air making it hard to achieve the desired vacuum 
(Taylor, 1995). An alternative to low-vacuum systems are Coanda grippers that utilize the Coanda, where compressed air flowing through a nozzle creates a secondary airflow that is used to lift the desired material (Lien \& Davis, 2008).

The cryo gripper works by spraying a contact fluid onto the material to be lifted and then putting the fluid in contact with a cold gripper surface, thereby freezing the material onto the gripper (Stephan \& Seliger,1999). The pickup sequence, depending on the material, takes several seconds (Taylor, 1995). The material is released by blowing air in the contact zone between the material and the gripper, and the release sequence is thereby quicker than the pickup (Stephan \& Seliger, 1999). The advantages with the technology is that is does not damage the material that is handled and it only require access to one side of the material. A disadvantage is the need for a contact fluid on the surface, which can contaminate the material.

In adhesive grippers a sticky surface is brought into contact with the material to be picked up, forming a bond between the gripper and the material. Adhesive grippers are not suitable for composite manufacturing because of the risk that the adhesive gripper material will contaminate the composite material (Taylor, 1995). There are adhesive grippers using surfaces with nanostructures, thus eliminating the contamination problem, but these technologies are not ready to be implemented in manufacturing equipment (Reinhart \& Straßer, 2011).

Electrostatic grippers are based on electrostatic attraction between the gripper surface and the material to be lifted. The attraction is usually created by applying a high voltage to the gripper surface (Kolluru et al., 1995; Monkman et al., 1989). The high voltage results in a need to insulate the system, and therefore the systems can become complex (Kolluru et al., 1995). Advantages with the gripping technology are that it does not damage the material, and that fast pick-up and drop-off times are possible (Kolluru et al., 1995; Monkman et al., 1989).

Clamping grippers are suitable to use if both sides of the material to be lifted are accessible. The gripping technology utilizes a mechanically-induced clamping force that in turn gives a friction force between the gripper and material, locking the aforementioned in place (Taylor, 1995). The great advantage with the technology is the simple release of material that is possible by just opening the gripper (Taylor, 1995). Needle grippers are also based on mechanically-induced friction, but in this case several small needles are inserted into the material (Taylor, 1995). This gripper type is commonly used in the textile industry. The 
material is easy to release by retracting the needles, however the needles can damage the material (Stephan \& Seliger, 1999).

\subsection{Ultrasonic CUTTING}

Trimming of preform edges is considered an important part of the second conceptual demonstrator that concerns automated preform manufacturing for RTM. Ultrasonic cutting is identified to be a possible enabling technology for the trimming operation in the conceptual demonstrator. Ultrasonic cutting is an established cutting technology where cutting blades tuned to a certain longitudinal resonance are used for cutting materials like food, wood, bones and composite materials (Lucas et al., 2006). The ultrasonic oscillations are in the range of $20-40 \mathrm{kHz}$ and the amplitude is in the $\mu \mathrm{m}$-range (Arnold et al., 2011; Thoe et al., 1998).

The effect of the ultrasonic excitation is dependent on many variables such as the geometry of the cutting blade, the frequency and amplitude of the vibrations and the direction of the vibrations relative to the cutting direction (Arnold et al., 2011). The detailed design of an ultrasonic cutting system, especially the horn, is a difficult undertaking that is usually done in an iterative way, with physical testing to find a solution that gives the desired amplitude at the tip of the knife (Lucas et al., 2001; Lucas et al., 2006). The use of ultrasonic vibration in cutting has, when testing other types of materials like foodstuff, been shown to drastically reduce the cutting force and the friction between the blade and the cut material, and it can also improve the quality of the cut surfaces (Arnold et al., 2011: Schneider et al., 2009).

Ultrasonic cutting is used for cutting prepreg plys in 2D cutting machines (Campbell, 2004). There are also examples of machines for three-dimensional cutting (American GFM) of composite materials, and of robot-mounted cutting systems used to trim plastic parts in the automotive industry (Bogue, 2008). 


\section{RESEARCH RESUlTS}

In this chapter, the results from the three conceptual demonstrators, dealing with automated layup of prepreg laminates, manufacturing of RTM preforms and adhesive joining of cured composite components, are presented. The chapter begins with a description of the manufacturing systems and types of automation currently used by the industrial partners. Thereafter, each conceptual demonstrator is briefly described. The background, results and experiences from the demonstrators are then presented, as well as thoughts on how off-the-shelf solutions contributed to the demonstrator results. The last chapter is dedicated to a summary of more general experiences and results concerning implementing off-the-shelf solutions for automated composite manufacturing based on the three conceptual demonstrators. Detailed results from each demonstrator are presented in the appended Papers I, II and III. 


\subsection{CURRENT TyPes OF AUTOMATION}

During the development of specifications for each conceptual demonstrator, as well as throughout a broad study of current practices performed as a part of the work presented in Paper IV, the current manufacturing processes of the three industrial partners have been studied. The current types of automation have been identified, and ongoing automation efforts and attitudes towards increased automation have also been noted. The results from these three cases can of course not be generalized to all composite manufacturing, but the findings are in line with other published observations, as shown in Section 4.1.4.

\subsubsection{IndUSTRIAl PARTNER FOR CONCEPTUAL DEMONSTRATOR 1}

The first industrial partner has a large workshop for manufacturing products based on various forms of prepreg. Large products with relatively simple geometry are manufactured using Automatic Tape Laying (ATL). The ATL machine is also used to manufacture flat laminates, which in a subsequent process are shaped using a heat-assisted version of vacuum forming called hot drape forming. Products with complicated geometries that cannot be manufactured by ATL are manufactured using manual prepreg layup. In some cases, the geometry is possible to manufacture using ATL, but due to product geometry the productivity will be very low. In some of these cases, the product is manufactured manually as the manual operation is assessed to be more costeffective.

Automated cutting machines are used for cutting the prepreg plys used in the manual layup operations. The cutting process is, despite the use of automatic cutting machines, heavily dependent on manual operations. Table 5 lists all of the tasks associated with ply cutting and shows if the task is performed manually or if it is automated. It is interesting to note that the real value-adding operation is the cutting of prepreg plys. The cutting process is automated, but connected to several tasks that are performed manually. 
Table 5: Automated cutting of prepreg plys.

\begin{tabular}{|l|c|c|}
\hline Operation & $\begin{array}{c}\text { Manual } \\
\text { task }\end{array}$ & $\begin{array}{c}\text { Automated } \\
\text { task }\end{array}$ \\
\hline Cover cutting table with protective plastic film & $\mathbf{V}$ & \\
\hline Put prepreg roll in cutting machine & $\mathbf{V}$ & \\
\hline Pull out material on cutting surface & $\mathbf{V}$ & \\
\hline Load program and find the start point & $\mathbf{V}$ & \\
\hline Cut plys & & V \\
\hline Label Plys & & V \\
\hline Remove cut plys, sort and place on material carrier & $\mathbf{V}$ & \\
\hline Cut off and remove scrap material & $\mathbf{V}$ & \\
\hline
\end{tabular}

Following the cutting process, there are two main types of manual prepreg layup. The plys can either be laid up directly on a shaping tool or laid up to form a plane laminate as a prior step to hot drape forming or vacuum forming. In the case where plys are directly put onto a shaping mold the product geometries are generally three-dimensional, but in preparing for hot drape forming the plys are stacked to form a plane laminate. There are examples of products where the manual layup of flat laminates prior to forming is more time-consuming then the forming operation which actually generates the final product. The high utilization of manual labor in removing and sorting material from the cutting machines, and the long layup times for flat laminates, indicate a possibility to increase the automation level in the current manufacturing system. Removing material from a cutting machine and layup of flat laminates can, to some extent, be seen as similar operations since both deal with pick-and-place of prepreg materials from one plane surface to another. The scope for the first conceptual demonstrator is a fully-automated system that cuts prepreg plys and lays up the plys to form flat laminates.

The machining of cured components is done in another workshop isolated from the composite manufacturing workshop, and has therefore not been studied. The industrial partner is involved in several research projects aiming to further increase the automation level within the composite manufacturing workshop. However, no physical demonstrators have yet been introduced into the workshop.

\subsubsection{IndUSTRIAL PARTNER FOR CONCEPTUAL DEMONSTRATOR 2}

The second industrial partner, involved in Conceptual Demonstrator 2, is in the process of building an automated manufacturing cell for preform manufacturing using the cut-and-paste method. The second conceptual demonstrator consists of 
the entire manufacturing cell, and an ultrasonic cutting demonstrator is intended to be an integrated part of the complete cell. The manufacturing cell for automated preform manufacturing includes an off-the-shelf conveyor cutting machine, a standard industrial robot, off-the-shelf ultrasonic cutting equipment and a purpose-built gripping device as well as compaction tools and a compaction press. Much of the development of the preforming cell has been made in different research projects but the manufacturing cell is, in its final version, intended for full-scale manufacturing. In the current manufacturing of preforms for RTM and the resin injection process itself, the industrial partner mainly relies on manual operations. For secondary processing after curing, like drilling and milling, semi-automated and fully automated machines are used.

\subsubsection{INDUSTRIAl PARTNER FOR CONCEPTUAL DEMONSTRATOR 3}

The industrial partner with the main focus on manufacturing products for space launch applications has the lowest automation level, with mainly manual operations. Semi-automated machines are used for machining, and some support systems like semiautomatic adhesive dispensing are used to support manual operations. The production volumes in the space industry are low since there are, as reported by Kyle (2014), less than 100 space launches per year. The low production volumes lead to a great variety of tasks to be performed on many different products. However, there are products like the demonstrator product, used for the third conceptual demonstrator, that can be manufactured using a large number of repetitive tasks, and therefore are interesting from an automation perspective. The company has recently started to look for automated solutions for some of the most repetitive tasks, and is involved in research projects that develop automation suitable for low-volume production.

\subsubsection{COnCluding Remarks on CURRENT Types of Automation}

To conclude, it can be noted that the overall level of automation differs greatly between the three industrial partners. One of the industrial partners uses both automated tape laying and automated ply cutting in their daily manufacturing operations, whereas the two other companies mainly rely on automated solutions for secondary processing like machining. All of the industrial partners are interested in further developing automation for the manufacturing of composite products and emphasize the importance of automation as a way of being competitive. They also express a wish to find automation solutions, like automated pick-and-place systems, that can be low-cost alternatives to ATL and AFP. 
The findings from studying the three industrial partners' current manufacturing systems are in line with those in the literature. Ward et al. (2012) note that several pick-and-place concepts for prepreg handling have been developed, but with limited impact on the manufacturing of composite products. The two main concepts that are commercially available are still ATL and AFP (Ward et al., 2012). An illustration of this is the manufacturing of components for the Airbus A350, where large structures like the wings and fuselage are manufactured using a combination of ATL and AFP technologies, and some of the reinforcing stringers are laid up to a flat laminate using AFP machines and then formed to the final shape using vacuum forming (Gardiner, 2011). For automated preform manufacturing using the cut-and-paste method there are commercially available alternatives, for example the composite handling system and the composite stacking systems from Broetje Automation (Broetje Automation, 2014; Broetje Automation, 2014b). However, automated preforming using the cut-and-paste method is not as well established as the ATL and AFP technologies.

\subsection{CONCEPTUAL DemONSTRATOR 1: AUTOMATED LAYUP OF FLAT LAMINATES}

The aim of the first conceptual demonstrator is a fully-automated manufacturing cell for layup of flat laminates that can be formed in a later processing step. The conceptual demonstrator and some of the results generated by building demonstrators for two of the enabling technologies are presented in the following chapters. Further details about the conceptual demonstrator and the enabling technologies can be found in Paper I.

\subsubsection{BACKGROUND}

The demonstrator products for the first conceptual demonstrator are four beams with rectangular cross-sections that are manufactured using an approach with the layup of plane laminates followed by vacuum forming. A time study of the current manufacturing process revealed that a considerable fraction of the total time needed for layup and vacuum forming of the four beams is spent on the manual layup of the laminates, as shown in Table 6 . The total time for layup and vacuum forming in Table 6 includes all the manual operations, starting from a sorted stack of cut plys ready for layup until the completed beams are sent off to the next step where they are assembled into a larger structure and then co-cured as a part of that structure. The processing time needed for the vacuum forming process is not included, as the manufacturing process is designed so the operator can work on another beam during the processing time. 
Table 6: Fraction of manual layup for four different beams.

\begin{tabular}{|c|c|c|c|}
\hline Beam & $\begin{array}{c}\text { Total time for layup and } \\
\text { vacuum forming [min] }\end{array}$ & $\begin{array}{c}\text { Time spent on } \\
\text { manual layup [min] }\end{array}$ & $\begin{array}{c}\text { Fraction of manual layup in } \\
\text { relation to total time [\%] }\end{array}$ \\
\hline A & 31 & 20,5 & 66 \\
\hline B & 32 & 21,5 & 67 \\
\hline C & 40,5 & 23 & 57 \\
\hline D & 52,5 & 34,5 & 66 \\
\hline
\end{tabular}

\subsubsection{DemONSTRATOR LAYOUT}

The process steps needed to automatically cut and lay up a flat laminate are outlined in Figure 24, while a possible layout of the conceptual demonstrator is shown in Figure 25. The conceptual demonstrator is intended to include a cutting machine, some sort of robot and an area where the laminates are laid up. The prepreg material used in the demonstrator is of the same type used for the current manufacturing of the demonstrator product. The prepreg is protected by a stiff backing paper on one side and is unprotected on the other side. Early on, in the conceptual development of the automated manufacturing cell, two enabling technologies were identified to be major challenges. The first enabling technology was a gripping tool that can be used to pick up prepreg plys, with varying geometry, from a flat surface and place them onto another flat surface. The second enabling technology was a system for automated removal of the backing paper that protects one side of the prepreg material. Paper I describes, in greater detail, the selection of gripping technologies and initial tests of various methods for automated removal of the backing paper. The results from the initial work in Paper I were further developed in a master's thesis project (Johansson \& Sundqvist, 2013) that resulted in a fully functioning prototype of the gripping tool with an integrated system for removal of the backing paper. 


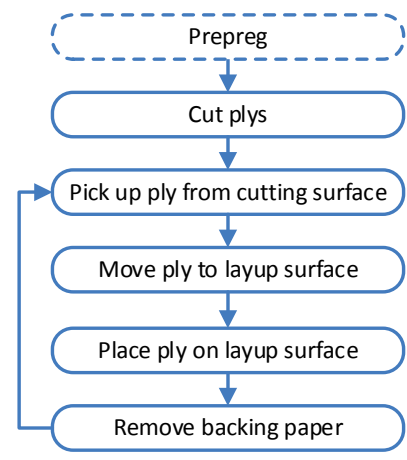

Figure 24: Process map of Conceptual Demonstrator 1.

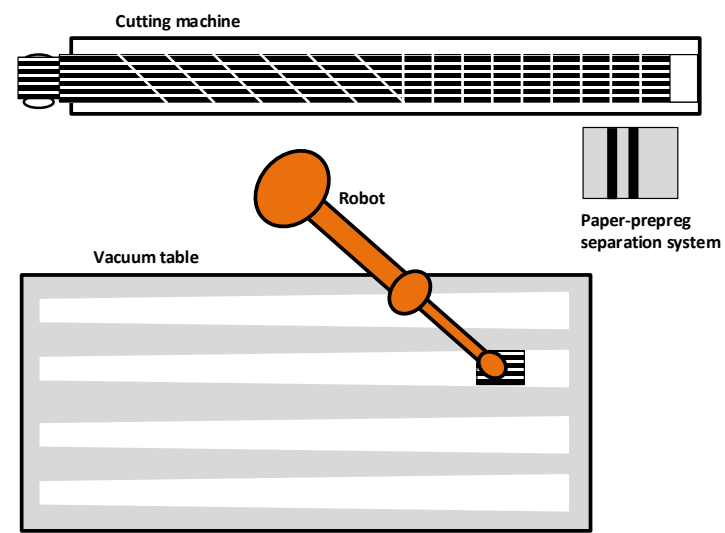

Figure 25: The selected layout for Conceptual Demonstrator 1.

\subsubsection{GRIPPING AND HANDLING}

The design of a gripping tool for the handling of prepreg material was simplified by the decision, made during the conceptual development of the automated manufacturing cell, to keep the backing paper during the handling operation and remove it after the ply has been placed on the layup surface. Keeping the protective backing paper helps to improve ply rigidity as it is handled, and since the gripping tool never needs to come into direct contact with the tacky prepreg, it also reduces the risk for material contamination and release problems. The improved rigidity can reduce the total number of contact points needed to lift the ply without deformations. The number of contact points needed in a gripping tool that is developed for the handling of prepreg plys with varying geometry has been shown to be greatly affected by the expected geometry variations between plys. Existing systems that can handle a great multitude of geometries become complex since they require a large number of contact points. Handling as rigid material as possible can therefore help in reducing the complexity.

Designing the process so that the material is cut with the protective backing paper facing upwards in the cutting process means that the plys never needs to be turned around, and the pickup tool can be designed so that the sensitive prepreg material never is in contact with the pickup points. However, keeping the backing paper introduced the need for an automated solution to peel off the backing paper after the ply has been placed onto the layup area. The decision to cut the prepreg with the backing paper facing upwards also set requirements on 
the cutting process, but the development of the cutting process is not included in the work presented here.

A review of different gripping technologies showed that vacuum grippers are suitable for the intended handling operation. The vacuum gripping technology is widespread, and there are a great number of commercially available gripper designs and materials to choose from. Other technologies were considered and rejected. Many of them were rejected due to the risk of damaging the prepreg, or of introducing contaminants to the laminate which are unacceptable due to the strict quality standards that are applied in the aerospace sector. Low-vacuum and Coanda gripping technologies were considered equally qualified as vacuum systems, but with fewer off-the-shelf solutions to choose from. Needle grippers, also a well-established technology, run the risk of damaging the prepreg. With cryo grippers there is a risk of introducing moisture to the material, while with adhesive grippers the release process can be difficult and the adhesive surface can, in direct contact with the prepreg surface, contaminate the material. Electrostatic systems were omitted due to their complexity, and non-contact grippers were unsuitable because of their lack of precision. Initial tests showed that vacuum grippers worked satisfactory for picking up prepreg plys from one plane surface and depositing them onto another flat surface. The prepreg attached to the backing paper proved to be rigid enough for handling, and no deformations were observed around the vacuum gripper.

\subsubsection{BACKING PAPER REMOVAL}

Based on the work done on the demonstrator for gripping and handling, vacuum grippers were tested for automated removal of the backing paper as well. Preliminary tests showed that the force generated by the vacuum gripper was not sufficient to separate the backing paper from the prepreg once the ply was placed and held in place on the layup surface. Another approach had to be pursued: either alter the bond between the prepreg and the backing paper or find another gripping technology. Preliminary tests showed that the bond between prepreg and backing paper is significantly weakened if the backing paper is separated from the prepreg and then reattached. As the tests showed that a vacuum gripper could separate prepreg from backing paper if they had previously been separated, this solution was pursued. The bond could also have been weakened by cooling the prepreg considerably. The cooling solution, however, conveys a potential risk for introducing moisture to the prepreg surface, and this risk is not acceptable with the current quality standards. The method to separate and then reattach the prepreg and the backing paper to be 
able to use vacuum gripper can be viewed as an enabling method for the backing paper removal demonstrator.

Equipment that separated and reattached the backing paper from the prepreg was developed. It was enough to create a separation on a small area, for instance one corner of the ply. A vacuum gripper could then be used to lift up the backing paper, at the previously separated area. After lifting the backing paper a peel motion was needed to remove the backing paper from the whole prepreg ply. The vacuum gripper, however, was shown to slide against the backing paper during the peel motion, resulting in unsuccessful removal of the backing paper. The solution was to combine the vacuum gripper with a mechanical clamping device. A pickup sequence for removal of the backing paper using this combination is illustrated in Figure 26 and described below.
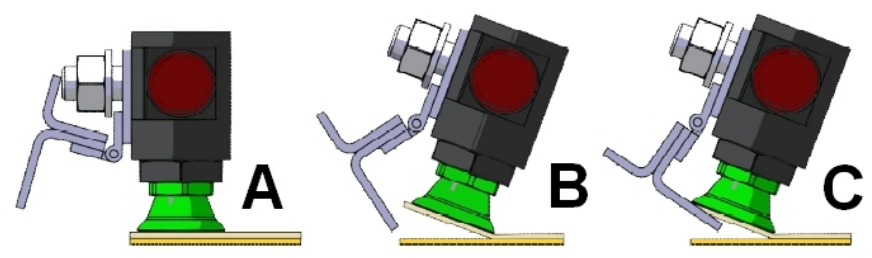

Figure 26: The pickup sequence for removal of the backing paper (Johansson \& Sundqvist, 2013).

A) A corner of the prepreg ply where the backing paper and prepreg have been separated and reattached is presented to the vacuum gripper.

B) The vacuum gripper picks up the backing paper, leaving the prepreg on the layup surface.

C) To create an extra strong grip a clamping device locks the backing paper in place. When the backing paper is secured, a peeling motion that removes the backing paper from the whole prepreg ply is initiated.

A prototype for separating backing paper and prepreg on a corner of a ply was built using simple components. Some of the components were off-the-shelf pneumatic components, while other components had to be manufactured specifically for the purpose. The prototype for creating the initial separation was built as a standalone unit rather than an integrated part of a gripping tool. The lifting tool needed for pick-and-place of prepreg plys, and the system for picking up the backing paper and clamping it for the peeling, were possible to integrate into the same gripping tool. The design of the gripping tool had to be adapted so one corner of the prepreg ply was accessible for initial separation 
using the standalone unit. The gripping tool, shown in Figure 27 and Figure 28, could be designed using a high degree of off-the-shelf components for both the vacuum system and the mechanical clamping device, as well as for the tool structure itself.

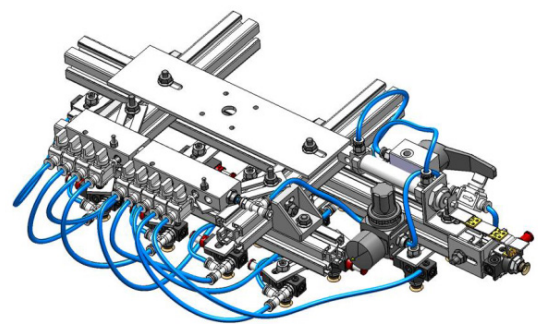

Figure 27: Digital model of a gripping tool. (Johansson \& Sundqvist, 2013)

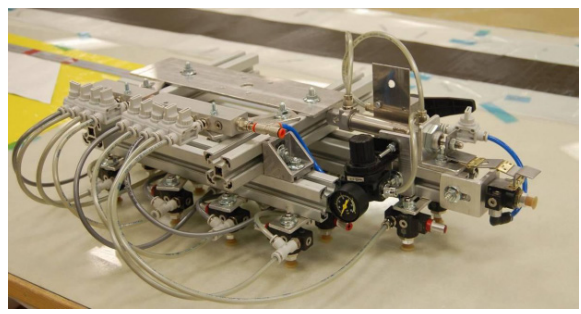

Figure 28: Photo of a gripping tool. (Johansson \& Sundqvist, 2013)

\subsubsection{Reflections on CONCEPTUAL DemONSTRATOR 1}

The work performed in the context of Conceptual Demonstrator 1 shows that off-the-shelf solutions can be used when developing automated solutions for composite manufacturing. It also illustrates some important factors concerning the use of off-the-shelf components. For example, design choices made in conceptual development, material properties and quality standards can all affect the ability to utilize off-the-shelf solutions. The overall design of the process, in this case done as part of the conceptual development, greatly influences the possibility to utilize off-the-shelf solutions. In this case, the decision to keep the backing paper until the prepreg is laid up simplifies the pick-and-place operation and the design of the gripping tool. However, it also resulted in the need for the enabling technology for automated backing paper removal as well as the enabling method concerning initial separation to be developed. In this case, a good understanding of the material properties and behavior of the prepreg proved to be essential for successful implementation. The backing paper peel-off was greatly simplified by the finding that the bond could be weakened using an initial separation. Using another material combination with a stronger bond between the prepreg and the backing paper might have called for another solution. A good understanding of quality requirements made the selection of a suitable gripping technology simpler, as many technologies were considered to bring about quality risks. The development using the vacuum gripper was greatly simplified by the fact that the gripping components were available offthe-shelf and could quickly be tested. 


\subsection{CONCEPTUAL DEMONSTRATOR 2: AutOMATED MANUFACTURING OF PREFORMS}

The context for the second conceptual demonstrator is a desire to develop a complete manufacturing system for automated manufacturing of products using RTM manufacturing technology. The manufacturing system is divided into two separate manufacturing cells: one manufacturing cell for the preforming operations and one for the molding operations. The second conceptual demonstrator was selected to be the preforming cell. The conceptual demonstrator in general and one of its enabling technologies, 3D ultrasonic cutting of preforms, are presented in the following chapters. More details on the demonstrator as well as on ultrasonic cutting can be found in Appended Paper II.

\subsubsection{BACKGROUND}

The manufacturing of the preforms is done according to the cut-and-paste method presented in Chapter 3.2.1. Layers of unidirectional carbon fiber reinforcement are cut and stacked to form a preform that is held together by a thermo-activated powder binder. The preform is then used in a molding stage, where it is placed in a mold and resin is injected to create the final composite product. The final product has rounded edges, and to avoid machining after the resin injection stage it is desirable to manufacture the final product with near-net shape. To do so, the preform must be manufactured to near-net shape so that it fits well into the injection mold. The preform can either be stacked directly to near-net shape or to a shape that is slightly larger than the real preform, and then trimmed to the final shape after the oversized preform has been compacted. The approach using an oversized preform is selected as it gives a simpler stacking process. The selected approach, shown in Figure 29, calls for a trimming stage, and ultrasonic cutting is identified as a possible enabling technology that can be used for the cutting of preforms.

A literature review of the field of ultrasonic cutting revealed very little published material on how ultrasonic cutting works and what process parameters affect the cutting result. The review also showed a tradition of empirical testing to find parameter settings that generate a good cutting result. The supplier of the ultrasonic cutting equipment used for the experiments had no previous experience with carbon fiber cutting and could only give general advice on how to set up the cutting process. Since no clear answers could be found, it was necessary to build a demonstrator to investigate if 3D ultrasonic 
cutting could be an enabling technology for the trimming operation needed in the conceptual demonstrator.

\subsubsection{Demonstrator Layout}

The conceptual demonstrator, shown in Figure 30, is comprised of a conveyor cutting machine for cutting of the reinforcement. A tool for picking and placing of the reinforcement has been designed using standard vacuum grippers assembled on a purpose-built structure. The pick-and-place tool is assembled on a standard industrial robot. The sheets of reinforcement are stacked in a tool and compacted during heating in a custom-built press to generate a preform that is rigid enough to be handled in the subsequent processing steps. Rather than buying a complete machine just for the trimming operation, a solution that is considered more suitable for the conceptual demonstrator is to buy ultrasonic cutting equipment and mount it on the robot that is also used for material handling in the conceptual demonstrator. This solution is also predicted to call for significantly lower investments. A switch between the pick-and-place tool and the ultrasonic cutting tool can easily be realized using a robotic tool changer system.

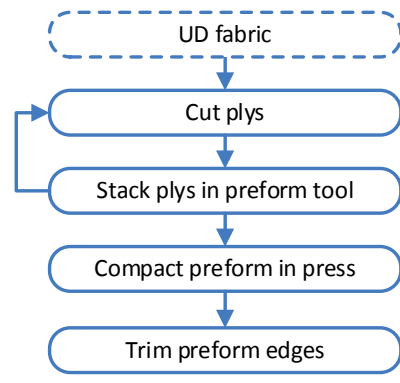

Figure 29: Flowchart describing the process steps in Conceptual

Demonstrator 2.

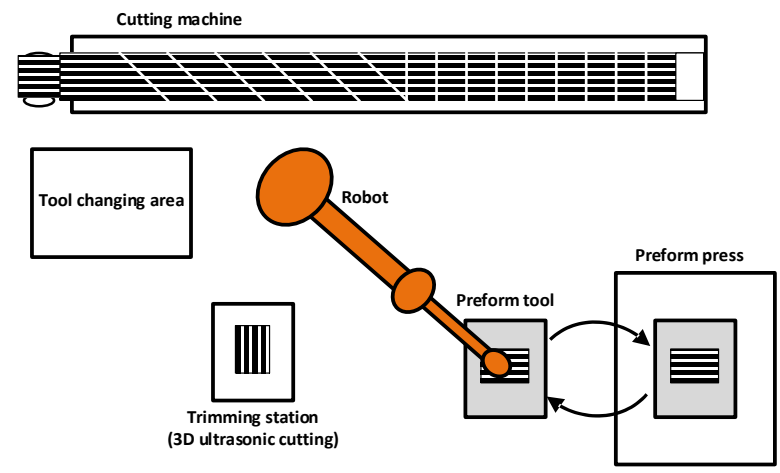

Figure 30: Layout of Conceptual Demonstrator 2.

\subsubsection{ULTRASONIC CUTTING}

As little published material on ultrasonic cutting could be found and the recommendations from the equipment supplier were limited, physical tests were conducted to evaluate if ultrasonic cutting could be used for $3 \mathrm{D}$ cutting of 
preforms. It was important to understand the cutting process and to determine how changes in the process parameters affected the cutting process and the quality of the cut. The tests were conducted using the same cutting equipment and robot that was intended to be integrated into the preforming cell. The same material to be used in the real product was used, but the geometry of the test preforms was simplified. The demonstrator setup that was used for the physical test, with the ultrasonic cutting equipment assembled on a standard robot, is shown in Figure 31.

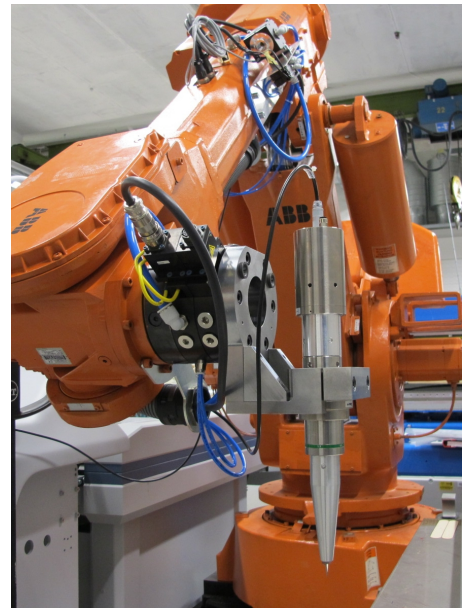

Figure 31: The demonstrator setup used for evaluating 3D ultrasonic cutting as an enabling technology for the conceptual demonstrator.

The tests showed that the physical setup and support of the preform during the cutting has great influence over the cutting result. Without proper support the preform deflects away from the ultrasonic knife, resulting in poor cut quality. The best cutting results are achieved using a support directly under the cutting line. The preform stiffness also proved to have a great effect on the cutting process. A stiff preform tended to deflect less during the cutting process, resulting in better cut quality. The test confirmed that it is possible to cut preforms using a chamfer angle. The rounded edge needed for the final product can be created using repeated cuts with varying chamfer angles, although this was not demonstrated during the tests. The test resulted in a set of process parameters that generated acceptable cutting quality for the test preforms.

\subsubsection{Reflections on CONCEPTUAL Demonstrator 2}

Working with the second conceptual demonstrator showed that choices made during the conceptual development have a huge effect on the possibility to use, 
and also the need for using, off-the-shelf equipment. The choice to manufacture the preforms to an oversized shape and then trim the edges to the final dimensions is of course very important in this case. If the choice would have been to manufacture the preform to near-net shape in the stacking sequence the trimming stage would not have been necessary at all, but the decision would most likely put new demands on the stacking procedure, thus affecting the use of off-the-shelf solutions for the stacking procedure. The test shows that ultrasonic cutting is an enabling technology for the conceptual demonstrator as it can be used in 3D cutting of preforms. The test performed on the ultrasonic cutting demonstrator showed that the material properties of the preform had a great effect on the cutting process. The material properties of the preform are, depending on previous processing steps in the conceptual demonstrator, like the preform compaction, and the properties have a large effect on the next step, in this case resin infusion. This means that all the processes in the conceptual demonstrator, as well as the processing steps following the preforming process, must be considered, and compromises might have to be made in order to facilitate the use of ultrasonic cutting without impairing the resin infusion step.

The physical test also indicated a need for good support during the cutting process. To use the tested off-the-shelf solution as a part of the preform manufacturing process, the fixture for holding the preform during the trimming operation must be designed to provide adequate support during the trimming operation. This fixture can be viewed as an enabling technology for the ultrasonic cutting. Although ultrasonic cutting is an established cutting technique there was little published material to be found that could be used to determine if the technology could be used for 3D cutting of preforms. Here, an advantage of using off-the-shelf solutions was the ability to easily procure ultrasonic cutting equipment and mount it on a standard industrial robot to provide a demonstrator for preliminary tests to evaluate the suitability of the technology.

\subsection{CONCEPTUAL DEMONSTRATOR 3:}

\section{ADHESIVE JOINING OF CURED MATERIAL}

The aim of the third conceptual demonstrator is an automated manufacturing cell that builds up the final product by adhesively joining cured composite components together. The conceptual demonstrator and the enabling technologies and methods are presented below. Some of the enabling technologies have been evaluated based on technical reviews using mainly published materials, but a few key technologies have also been investigated 
using physical tests and a physical demonstrator. Further information about the third conceptual demonstrator can be found in Paper III.

\subsubsection{BACKGROUND}

In the case of the third conceptual demonstrator the forecasted manufacturing volume of the selected case product is very low. However, the intended manufacturing process of the case product is of a repetitive nature, and requires a great number of similar tasks to be performed with high repeatability and high quality. The required quality and the high number of repetitive tasks are the main reasons for developing the automated solution in Conceptual Demonstrator 3.

The fundamental idea behind the conceptual demonstrator is to build the ringshaped structure by joining equally shaped building blocks of cured composite material together and at the same time place them onto the truncated cone. A more traditional approach would have been to manufacture the entire ring of uncured composite material and then assemble the ring onto the truncated cone once the ring was cured. The building blocks, simply denominated blocks, can be manufactured by cutting out the block shape form flat laminates of cured composite material. The blocks can be assembled to the final product using adhesive joining. The demonstrator uses the blocks as input material and does not include the manufacturing process of the blocks.

\subsubsection{DEMONSTRATOR LAYOUT}

Several concepts for the automated manufacturing cell were developed and analyzed. To automate the assembly of the blocks the following processing steps must be performed in an automated way. Some sort of gripping is needed to pick up and place the blocks, and robotic manipulation is needed to move the blocks within the manufacturing cell. The blocks need to be thoroughly cleaned before an adhesive is dispensed. The blocks are finally placed in some sort of fixture or jig until the adhesive has cured. For each of these processing steps, shown in Figure 32, enabling technologies and methods must be considered. The enabling technologies are analyzed from a technical perspective, using literature reviews, more general technology reviews and physical tests to investigate how off-the-shelf solutions can be used for each enabling technology. An example of a possible layout of Conceptual Demonstrator 3 is illustrated in Figure 33. 


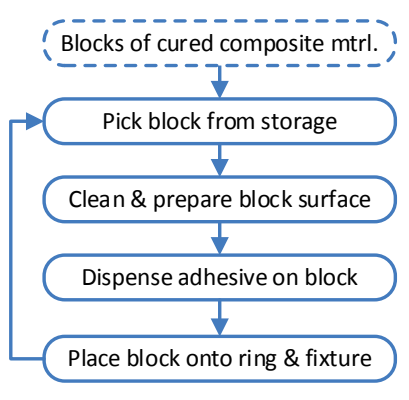

Figure 32: Flowchart describing the process steps in Conceptual Demonstrator 3

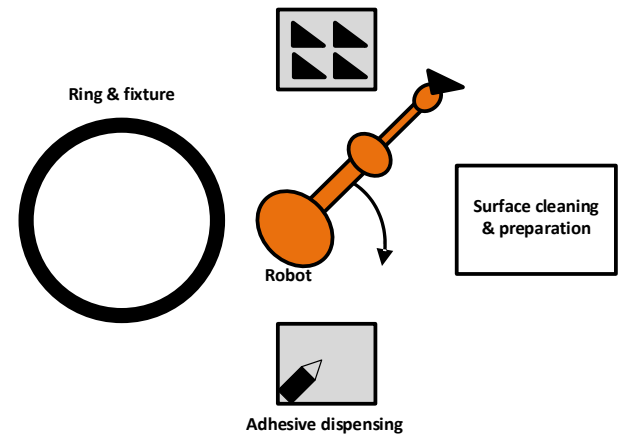

Figure 33: Layout of Conceptual Demonstrator 3.

\subsubsection{Gripping, Manipulation and FiXture Design}

For the robotic manipulation, it is clear from the specifications of the final product and published information about robot performance that off-the-shelf equipment could be used. The same conclusion could be drawn when analyzing the robotic gripping. A standard vacuum gripper would fulfill the requirements.

The fixture must be fully adapted to the geometry of the blocks and the final product, as well as adapted to the adhesive joining process, so that the fixture itself does not adhesively join to the rest of the assembly. The fixture must therefore be purpose-built and cannot be an off-the-shelf solution.

\subsubsection{SuRface PREPARATION}

In adhesive joining of composite material it is very important to thoroughly clean and prepare adherend surfaces. There are, as described in Chapter 3.3, a number of methods available for cleaning and surface preparation. As no detailed material specifications were available for the block material, no detailed investigations were made in the field of surface cleaning and preparation. However, on a general level it can be concluded that there are some surface cleaning and preparation methods that offer technical off-the-shelf equipment that can be integrated in an automated manufacturing cell, while other methods would require development of automated solutions.

\subsubsection{ADHESIVE DiSPENSING}

At first glance the deposition of adhesive onto the surface, i.e. the dispensing, seems a simple task to automate. There are off-the-shelf systems available for fully-automated dispensing as well as systems for semiautomatic dispensing. In 
the fully-automatic case a machine, usually a gantry robot, moves the dispensing unit in a programmed pattern while dispensing a well-defined amount of adhesive. In the case of a semiautomatic solution the dispensing unit only controls the amount of adhesive to dispense. The motion has to be generated by another machine or by a human operator. However, even if the equipment for automatic adhesive dispensing is available off-the-shelf the dispensing process must be adapted to the material and adhesive at hand, as well as to the fixture solution and the selected gripping method. Tests indicate that there are two main challenges in automating the adhesive dispensing: the adhesive must be dispensed in a pattern that gives the desired area coverage without voids, and the application must be done without smearing or dripping adhesive on surfaces other than the intended adherends.

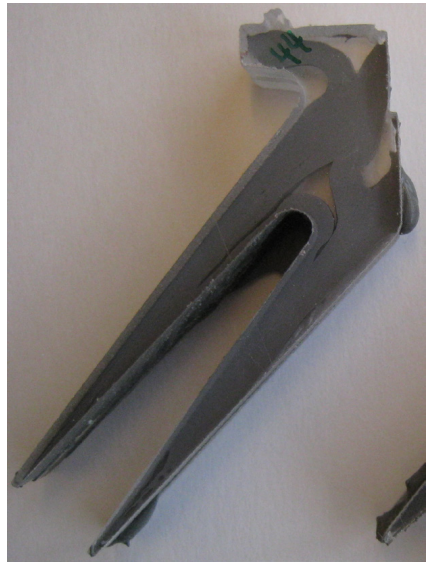

Figure 34: Voids and uncovered areas as a result of a poor dispense pattern.

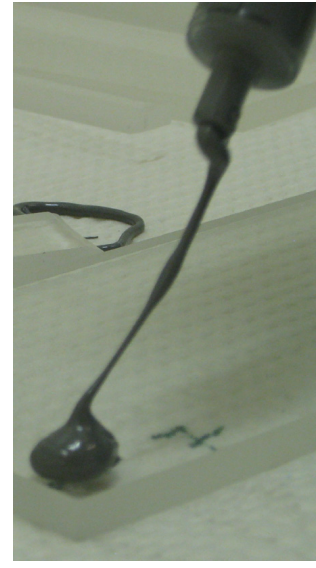

Figure 35: A string forming from the adhesive dispensing area and the dispenser.

The dispense pattern affects how the adhesive flows when the two adherend surfaces are brought in contact. A poor dispense pattern has been shown to generate voids and areas without adhesive in the adhesive bond, as shown in Figure 34. Voids and uncovered areas will affect the strength of the bond. The application pattern and the amount of applied adhesive affect the flow of adhesive when the two adherends are put into contact with each other, and can therefore affect how excess adhesive is pushed out of the bond. This, in turn, can affect the desired fixture design. The adhesive dispensing process must be developed based on the materials and geometry of the products to be joined. 
For high viscosity adhesives, tests show that there is risk of a string of adhesive forming between the application nozzle and the adhesive dispensed on the adherend surface when the nozzle is removed after application. This string, shown in Figure 35, can contaminate areas that should not be in contact with the adhesive. The tendency to form a string between the adherend surface and the application nozzle after completed application has shown to be dependent on how the application is done, how the nozzle is removed after application and the diameter of the nozzle. In order to create a highly repeatable automated process the strings need to be either eliminated or controlled in a repeatable way. Therefore, it is necessary to develop a dispensing method that is adapted to each current case.

\subsubsection{Physical Demonstrator}

One part of the conceptual demonstrator has been realized in the form of a physical demonstrator. The physical demonstrator includes the pickup of blocks, the adhesive dispensing onto the blocks and the placement of the blocks onto a segment of a truncated cone. The demonstrator, shown in Figure 36, 37 and 38, features a standard industrial robot for the robotic manipulation. The gripping is realized using a vacuum gripper and ejector. The adhesive is dispensed using a standard stationary semiautomatic dispensing unit, and the motion needed for the dispensing pattern is done using the robot. A mockup segment of the truncated cone is used instead of the full-sized cone. A fixture, adapted to the mockup segment, fixates the blocks' position relative to the segment.

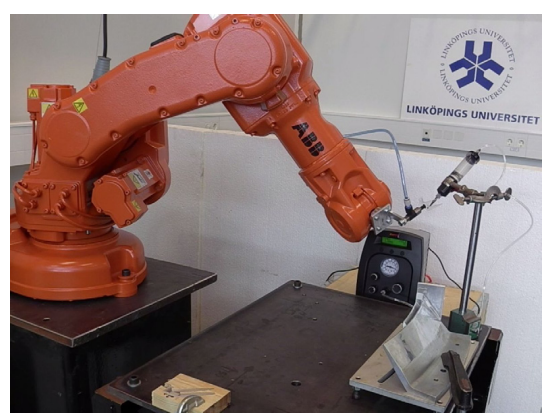

Figure 36: The physical demonstrator for adhesive application.

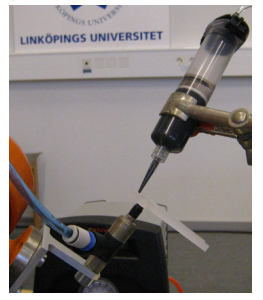

Figure 37: Close-up on the gripper and the dispensing unit.

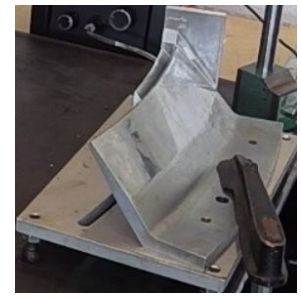

Figure 38: Close-up on the mockup segment and the fixture.

The physical demonstrator showed that off-the-shelf solutions could be used for gripping and manipulation as well as for the adhesive dispensing. However, the 
method, i.e. application pattern, of dispensed adhesive had to be developed for the particular case. The work on the physical demonstrator also showed that in designing the gripper and manipulation solution the adhesive dispensing and the fixture design must be considered. The gripper must be able to present all the areas to be covered with adhesive and also position the block in the fixture without being contaminated by adhesive or colliding with the fixture. The motion to place the block in the fixture must be carefully designed so that the adhesive on the block surface is not smeared onto the wrong areas, and so that the block is positioned with the right pressure onto the previously placed blocks so that the adhesive distributes well in-between two blocks.

\subsubsection{Reflections ON CONCEPTUAL DemONSTRATOR 3}

Although the final product is manufactured in very low volumes, the industrial partner expressed an interest in finding an automated manufacturing system suitable to manufacture the product. This was because the manufacturing could be broken down into rather simple tasks that have to be repeated a great number of times to manufacture the product. The breakdown into small tasks simplified the search for enabling equipment and methods to solve each task. The third conceptual demonstrator highlights the material properties' effect on the possibilities to utilize off-the-shelf equipment. This is especially clear when looking at the method to use for surface cleaning and preparation. The method is dependent on the block material, and for some methods there exists technical equipment that can be easily integrated in an automated manufacturing cell. Other methods would, however, require development of enabling technologies for automated manufacturing. The design of the physical demonstrator shows how decisions regarding the design of one enabling technology affect the possibility to design the others, and by that can affect if off-the-shelf solutions can be used. This is the case when designing the gripper and the fixture in connection to developing the methods for adhesive dispensing.

\subsection{IMPLEMENTING OFF-THE-SHELF SOLUTIONS}

Working with implementing off-the-shelf solutions for the three conceptual demonstrators has brought to light several important aspects that are similar among the three conceptual demonstrators. For example, the work with the demonstrators has shown that general quality demands and requirements on validation of changes to current products or processes affect implementation of automated manufacturing based on off-the-shelf solutions. The conceptual demonstrators have also illustrated that product design and material properties affect the ability to use off-the-shelf solutions, and that the whole manufacturing 
process must be considered in designing automated solutions. These similar aspects among the three conceptual demonstrators are presented in greater detail below, together with an approach that simplifies the selection of suitable offthe-shelf solutions. The section is concluded with a summary of what aspects affect if off-the-shelf solutions can be used to automate composite manufacturing, and what advantages can be gained in using off-the-shelf solutions for automation.

\subsubsection{VALIDATION}

One issue that is always very relevant in developing automation solutions, or working with any changes of the current manufacturing processes within the aerospace industry, is the validation of product designs, manufacturing methods and technologies. Changes to a manufacturing system must in most cases be validated according to a standard process to make sure that they do not affect the quality of the final product. The validation process can range from showing theoretically to demonstrating through an extensive testing program that the quality of the final product will not be influenced by the change. The extensiveness of the validation process is dependent on many factors, and it is important to be aware of the need for validation. Some examples of factors that affect the validation process, and more details on how changes in production can lead to validation, are given in Paper IV. Designing processes that are an automated version of today's manual process might lead to a lower level of validation, but on the other hand that process might not be as efficient as newly developed methods. Likewise, the use of off-the-shelf solutions that can be well-established in areas other than automated composite manufacturing might simplify the validation process, since there is a basic understanding of the technology and experiences from other areas to draw conclusions from, but the extent of a validation process is still determined on a case-by-case basis.

\subsubsection{QuALITY REQUIREMENTS}

The rigorous quality requirements and quality standards within the aerospace industry affect the possible manufacturing processes. They can, in some cases, affect if off-the-shelf solutions can be used or if new solutions with capabilities other than the available off-the-shelf solutions need to be developed. For example, some operations must according to quality be inspected manually. This is the case for the layup of flat laminates in the first conceptual demonstrator. The process must be designed so that no foreign objects, for instance pieces of backing paper, are built into the laminate as it is laid up. Currently, the manual operators assure this by means of optical inspection during the layup. To fully automate the layup an inspection system that can 
identify foreign objects must be included in the automated solution. In other cases, it can be enough to show a high level of process reliability to avoid secondary control systems. Another example on how quality standards affect the automation solution is the requirement that the material silicone is not allowed to be used in contact with prepreg materials or in contact with surfaces that are to be joined in an adhesive bond. This requirement affected the selection of vacuum grippers for Conceptual Demonstrators 1 and 3, since silicone is a common additive in materials used for vacuum grippers.

\subsubsection{Product Design}

Product design, in this case including both the geometrical shape and the material selected for the product to be manufactured, has a great effect on how to automate the manufacturing process and if off-the-shelf solutions can be used. The geometrical shape of the demonstrator product in the first conceptual demonstrator makes the product impossible to manufacture using an ATL layup. Since the well-established ATL technology cannot be used it is interesting to investigate a pick-and-place concept for automated manufacturing. In the third conceptual demonstrator it is the strength requirements of the final product that allow for an innovative product design, resulting in the conceptual manufacturing process of adhesively joining standard blocks to manufacture the final product. The selection of material used in the blocks also proved to greatly affect the possibility to use off-the-shelf solutions.

\subsubsection{MATERIAl Properties}

Composite materials show a great variety of material properties, some of which have a great effect on what type of off-the-shelf solutions can be used to automate a manufacturing process. For example, different combinations of prepreg and backing paper form bonds of different strengths. For the material used in Conceptual Demonstrator 1 the bond was so strong that a vacuum gripper could not separate the paper from the prepreg, which resulted in the development of a secondary process for initial separation. For another combination of prepreg and backing paper that forms a weaker bond, this extra process for initial separation might not be necessary. A detailed understanding of the material behavior is also important in designing automated manufacturing processes. The peeling of the backing paper in the first conceptual demonstrator is done along the fiber direction. Peeling in other directions can result in damage to the prepreg material, since the material is significantly weaker in all directions apart from the fiber direction. 


\subsubsection{Manufacturing System Perspective}

It is important to consider all the steps in the manufacturing process since they affect each other. A systems perspective must be used where the complete manufacturing system always is considered. A solution that will simplify automation and the use of off-the-shelf solutions for one processing step can affect another processing step in a negative way. One example of this can be illustrated using the second conceptual demonstrator. The level of compression of the preform affects the preform stiffness and in turn its ability to deflect, but at the same it will affect the preform permeability and thereby the resin injection in a later step of the RTM process. The level of compaction, therefore, might have to be a trade-off between the desire to manufacture a stiff preform that is simpler to trim, and a less compacted preform that is desirable in the resin injection process.

In order to use of off-the-shelf components it might be necessary to adjust the planned process, or to design extra equipment to support the off-the-shelf solution. In the case of prepreg pick-and-place, a machine for initial separation was developed so that standard vacuum grippers could be used for lifting and removing the backing paper. In the case of preforming, the fixture needs to be designed to provide adequate support during the cutting operation to allow for ultrasonic cutting to be used.

The manufacturing volume that the manufacturing system is designed to handle naturally affects what type of automation is needed. A basic idea for the second conceptual demonstrator is to use the same robot both for pick-and-place of fabric and for ultrasonic cutting. This requires the ability to change tools between the two tasks. With an increased manufacturing volume the time would not be sufficient for the same robot to perform both tasks with a timeconsuming tool change. Another solution rather than robot-held ultrasonic cutting could then have been pursued. The third conceptual demonstrator shows that it is not necessary with a high manufacturing volume of the final product to make automated solutions interesting. In the third demonstrator it is the high number of repeatable tasks that renders automation interesting.

The dual use of the industrial robot in the second conceptual demonstrator also illustrates that many of the off-the-shelf solutions are general. These general solutions can fulfill several tasks within an automated system for composite manufacturing. 


\subsubsection{Suitable Approach When Working With OFF-THE-SHELF SOLUTIONS}

All the conceptual demonstrators have been broken down into basic, rather simple tasks that are shown in the process flowcharts for each conceptual demonstrator. Picking and placing is a task shared by all three conceptual demonstrators, and even though the handled material differs it is possible to transfer knowledge and experiences from one demonstrator to another, for example in the case of gripper technologies. The breakdown into simple tasks can help in finding comparable tasks in other demonstrators, as well as in automated solutions used for types of manufacturing other than composite manufacturing. By breaking down complex sequences into basic tasks and studying each task in detail, the implementation of off-the-shelf technology has been aided, since solutions from other applications could be used.

An advantage of using off-the-shelf solutions is that in most cases there is published material on equipment specifications that can help in early conceptual development. However, since the off-the-shelf solutions in the conceptual demonstrator cases are intended to be used in new ways or for new materials as they are taken from an established use to be used in automation of composite manufacturing, this means that there is generally only basic information about the technology available. It is hard to find any published material within the exact intended use. However, since the off-the-shelf solutions are commercially available it is possible to rent or purchase equipment for initial tests. During the work with the demonstrators, simple tests have shown to be a good indicator of if the technology is possible to use for the intended use. 


\subsubsection{SUMMARY}

To summarize the results from the three conceptual demonstrators, the aspects that affect how off-the-shelf solutions can be implemented when automating composite manufacturing are:

- Quality aspects

- Requirements for validation of new products or processes

- General quality requirements

- Product aspects

- Product design

- Material properties

- System aspects

○ Tasks needed to be performed

- Tradeoff between requirements set by each task

- Expected manufacturing volume

By using off-the-shelf solutions when designing systems for automated composite manufacturing the following advantages can be gained:

- Low investment cost for off-the-shelf technologies

- Information about off-the-shelf solutions is readily available

- Technologies are generally available for physical tests

- General technologies that can fulfill several tasks in the automated system 


\section{CONCLUSIONS AND Discussion}

This chapter begins with a concluding section, where answers to the research questions are proposed and more general conclusions are provided. Following that, the results and conclusions as well as the methods used are discussed. After the discussion the contributions to both industry and academia are discussed, and an outlook towards future research is presented. 


\subsection{CONCLUSIONS}

To conclude the previous chapters, and to connect the results to the research aim presented in the introductory chapter, the three formulated research questions are answered in turn below.

RQ1: What types of automation are used within the industrial partners' existing manufacturing systems?

Varying types of automation can be found in the industrial partners' existing manufacturing systems. One industrial partner utilizes automated tape laying as well as automated ply cutting, while the two other industrial partners mainly use automatic or semiautomatic machines for secondary processing once the composite material has cured. It can be noted that the automated ply cutting operation is supported by several manual tasks, in particular material handling tasks. All the industrial partners express an interest to increase the automation level in their composite manufacturing processes in general, and foresee automated solutions associated with low investment costs as an interesting alternative to established technologies like ATL and AFP. One partner is developing a cell for automated manufacturing of preforms based on off-theshelf solutions. However, there are no automated manufacturing solutions based on a high degree of off-the-shelf solutions utilized in the existing manufacturing systems.

RQ2: How can off-the-shelf solutions be used when developing automated manufacturing for composite products?

The three conceptual demonstrators have shown that it is possible to create automated manufacturing cells for the layup of flat laminates based on prepreg material, manufacture of RTM preforms and adhesive joining of cured material using a high degree of off-the-shelf solutions. It has been shown advantageous, in order to find suitable off-the-shelf solutions, to break down the intended automated cell into basic tasks. Off-the-shelf solutions can then be considered for each particular task. However, in some cases it has been necessary to alter the task or to add additional tasks or equipment in order to allow for the use of off-the-shelf solutions. Different levels of off-the-shelf solutions can be used in automating different tasks. Some of the tasks can be solved by implementing complete off-the-shelf systems. In other cases it might be necessary to design purpose-built equipment, but this equipment can be based to a high degree on off-the-shelf components. There are cases where off-the-shelf technologies can be used, but the method that utilizes the technology must be adapted to the 
current case. It has proved to be important to consider the use of off-the-shelf solutions early in the conceptual development of the entire manufacturing cell since decisions made during the conceptual development affect the ability to use off-the-shelf solutions.

RQ3: What challenges are associated with the use of off-the-shelf solutions for automated composite manufacturing?

The three conceptual demonstrators have illustrated some of the challenges in trying to bring off-the-shelf solutions, in many cases developed for other types of manufacturing, into a composite manufacturing system. One challenge in composite manufacturing is the great variety in material properties. In the demonstrators tacky prepreg, highly permeable dry fiber reinforcement and cured composite material have been handled. Each of the materials has brought about separate challenges in finding suitable off-the-shelf solutions. The possibility to easily procure off-the-shelf solutions for physical tests has been shown valuable in dealing with the great variation in material properties.

Solutions developed for one demonstrator might be difficult to generalize for reuse in other demonstrators because of differences in material properties or product geometries for different product demonstrators. In an automated manufacturing cell for composite manufacturing several tasks will have to be performed in order achieve the final product. Understanding each of these tasks and how they affect each other has proved to be a challenge. Decisions that might facilitate the use of off-the-shelf solutions in solving one task, for example, might obstruct the use of off-the-shelf solutions for solving another. Other challenges, mainly caused by the work being performed within the aerospace industry, are the high quality demands and the requirements for extensive validation of new processes or materials. Prevailing quality demands might exclude certain types of off-the-shelf solutions, and the demands for validation will affect the time and cost for implementing new automated manufacturing solutions.

\subsection{Discussion}

Campbell's (2004) example showing that, in the case of manual prepreg layup, cutting and layup account for $40-60 \%$ of the manufacturing cost of a part illustrates the need for developing automated solutions. The industrial partners have expressed a need for automation technologies that are complementary to the advanced technologies like ATL and AFP, and that are associated with lower investment costs. The demonstrators have shown that it is possible to use 
off-the-shelf solutions when building automated manufacturing cells for automated manufacturing of composite products. The results from the demonstrators also point to off-the-shelf solutions as a low-cost alternative. However, the studies of the current manufacturing processes within the three industrial partners' existing manufacturing systems show very little use of offthe-shelf of solutions. This is supported by findings from literature reviews that indicate that composite manufacturing, in particular manufacturing based on prepreg, are in most cases either manual or automated by ATL and AFP.

In other industrial sectors, the approach to building automated solutions based on off-the-shelf solutions is a more established tradition than within composite manufacturing where complex solutions like AFP and ATL are dominant. Automated manufacturing processes built on off-the-shelf solutions fill an important gap by providing automated solutions with lower investment costs. Despite the advantages of using off-the-shelf solutions for automated composite manufacturing this approach is unusual in today's manufacturing systems. Possible reasons for the limited use of off-the-shelf solutions within composite manufacturing can be the high quality demands and validation requirements for new manufacturing technologies or processes, and the great variety in material properties and manufacturing processes that can be found in composite manufacturing. The strict demands for validating new manufacturing processes or technologies make development and implementation a tedious and rather costly business, and it can hamper the development towards more cost-efficient manufacturing of composite materials. The great variety in material properties and manufacturing processes makes it difficult to fully reuse developed solutions among different products or manufacturing processes.

The definition of off-the-shelf solutions, provided in Chapter 1.5, divides the solutions into two major groups, technologies and methods. Off-the-shelf technologies can, in turn, be divided into subgroups as illustrated in Figure 6. This subdivision is much inspired by Groover's (2008) levels of automation that were presented in Table 4. Off-the-shelf methods are likewise divided into the subgroups of processes and procedures. For both off-the-shelf technologies and methods it has, in some cases, been shown to be difficult to determine if a technology or method can be considered off-the-shelf. The main rule of thumb is that if a technology or a method needs detailed development it is not considered off-the-shelf. However, whether or not a technology or a method is off-the-shelf, strictly according to a narrow definition, is not of great importance. It is the general view, to utilize already existing technologies and methods, that is the main point. 
Automated handling of material is a task that is shared among the three conceptual demonstrators, and material handling in general is a task that is frequent in composite manufacturing. The conceptual demonstrators have shown that it is possible to handle prepreg, dry fiber reinforcement and cured composite material by using off-the-shelf vacuum systems. In the third conceptual demonstrator all the blocks that are handled have the same geometrical shape, while the first and second conceptual demonstrators need to manage a variety of geometrical shapes. The gripping tools used for the first and second conceptual demonstrators show that an increased demand for flexibility (in the first two conceptual demonstrators a demand to handle a variety of geometrical shapes) the more complex the tool becomes. To handle more shapes the number of contact points, in this case the number of vacuum grippers, needs to be increased as illustrated in Figure 39. To allow for cases where adjacent pieces of material are handled, each contact point must be individually controlled so that it can be turned on or off. An increased number of individually controlled contact points leads to a complex design of the complete gripping tool. However, the handling task is itself simple; the complete gripping tool can be built by using uncomplicated off-the-shelf components, but the complete gripping tool becomes complex in order to handle the variety.

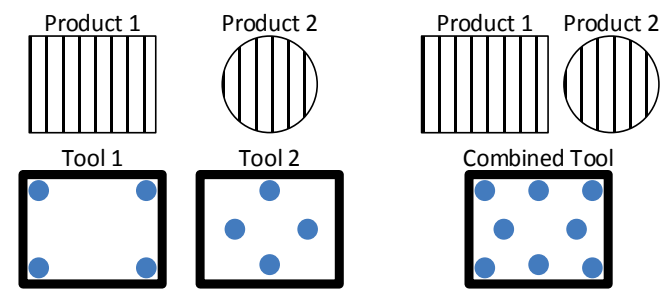

Figure 39: Combining the contact points (blue circles) needed for Products 1 and 2 into one gripping tool that can handle both products.

Several concepts for pick-and-place can be found in published material, but many of them share the same challenge of increased tool complexity with increased flexibility. This can be one of the reasons hampering the implementation of pick-and-place concepts in existing manufacturing processes. The basic idea of achieving the flexibility to handle diverse geometrical shapes by building complex gripping tools is an interesting challenge for a future research project. Industrial robots are used to manipulate the gripping tool in all of the three demonstrators. Rather than building the flexibility into the tool, it might be possible to utilize the robot's reprogramability to handle the changes in 
geometrical shapes, and thereby reduce the need for flexibility in the gripping tool.

The prevailing quality requirements for all three conceptual demonstrators are high because of the general quality level within the aerospace industry, but also because the demonstrators are within the field of composite manufacturing. It is sometimes hard to distinguish between the quality requirements that stem from the general quality level within the aerospace industry and those that are only applicable for the manufacturing of composite products, but both types will affect the design of an automated manufacturing solution. It is important to understand the difference when implementing off-the-shelf solutions from composite manufacturing for applications other than aerospace, or when exporting solutions developed within the aerospace domain to other types of applications.

Due to the demanding quality requirements much time is spent on quality inspections of final products, but also during the manufacturing process to verify the quality of processing steps. One example of this is the manufacturing of flat laminates in the first conceptual demonstrator, where the operators continuously check the laminate for wrinkles and air bubbles during the manual layup. The operators also ensure that all the backing paper is removed before a new ply is placed onto the laminate. This type of manual, continuous quality control in an automated solution should probably be replaced with an automated solution to be able to validate the automated manufacturing solution. Commercially available off-the-shelf systems for automated quality inspection exist, but adapting them to a specific manufacturing process and integrating them into a fully automated manufacturing cell will most probably require a development effort.

Moving from fully manual manufacturing to fully automated manufacturing is in many cases considered to be very risky, and therefore intermediate steps with demonstrators showing each part of the system to be realizable might be necessary. Off-the-shelf solutions are available for testing a new technology or idea in the form of a physical demonstrator. This ability to run simple tests has a positive effect on automation of composite manufacturing as it lowers the threshold for testing new technologies for automation. Companies with low production volumes and extensive quality requirements can evaluate a technology's feasibility on a small scale, and if it is successful continue the development of an entire system for automated manufacturing. 
None of the conceptual demonstrators were fully realized to a stage where the entire manufacturing process could be tested in order to find out the maximum production capabilities. All the demonstrators need further development before this type of testing can be realized, and that development will add cost for development and hardware that is, at present, difficult to estimate. Therefore, detailed cost analyses for the conceptual demonstrators have not been performed.

So far, many of the aspects that are summarized in Chapter 4.5.7 and that affect if off-the-shelf solutions can be used are case-specific, depending on for example the product geometry, what materials are used, what production volumes are expected and what quality standards apply to the product and the manufacturing processes. Since most of these aspects are case-specific it is difficult to generalize to other cases, but a further, more detailed study of the aspects might reveal common denominators that can lead to more generalizable results. Based on those results, it might be possible to develop guidelines to use as many off-the-shelf solutions as possible when designing automated manufacturing systems. With the increased use of off-the-shelf solutions for automated composite manufacturing comes an increase in published information. Given a growing number of published results, within the field, it might be possible to further analyze common denominators between different cases and develop general guidelines on what aspects influence the ability to use off-the-shelf solutions and how to utilize off-the-shelf solutions for automated composite manufacturing.

\subsubsection{Discussion of Research ApProach AND METHOdS AND TOOLS USED}

The research described in this licentiate thesis can be categorized as applied research, and the main focus has generally been the solving of specific problems in real-life situations, rather than the formulation of theory or contributions to fundamental knowledge. This is in accordance with the definition of Williamson et al. (2002) on applied research. The approach that has been used in developing the demonstrators has been inspired by the cyclic nature used in the action research approach. The demonstrators have been developed in several design iterations, and test results and experiences from one iteration have guided the following development.

Using the demonstrator-centered research approach has in several aspects been shown to be very valuable for the research presented in this licentiate thesis. First of all, the idea to base the conceptual demonstrators on an industrial 
challenge has generated high interest from industrial partners, and also ensured that the demonstrators generated knowledge that is relevant for both industrial and academic partners. The demonstrator itself also proved to bridge the gap between the industrial and academic partners, and helped to coordinate the necessary research and technological developments towards a concrete goal, the manufacture of a physical demonstrator. The tight industrial collaboration provided very valuable access to the industrial knowledge base that could have been difficult to access without the established collaborations between academic and industrial partners. The physical demonstrators have been used for experimentation and evaluation, and thereby generated valuable research data that has been published in the appended papers. At the same time, the conceptual demonstrators have shown the feasibility of several technical concepts to the industrial partners. This is an important step towards implementing the technology in full-scale manufacturing.

The development of the specifications and the early work to understand the industrial context for each demonstrator has also given valuable insights of the current automation level in composite manufacturing. Information on the general level of automation has been collected by means of interviews and observations of the current manufacturing processes of the three industrial partners involved in the demonstrators. The information collected from observations and interviews was compared to findings from literature reviews within the field of automation of composite manufacturing. The findings from the interviews and observation were in line with the published findings and indicated that, especially for low and medium-volume manufacturing, there is potential for developing automated solutions if it can be done in a cost-efficient way.

Some of the results from the demonstrators have been shown to be generalizable to a level where detailed knowledge gained from the work on one demonstrator could be transferable to another. An example of this is the gripping of material and robotic manipulation that is present in all the demonstrators. Although handling different materials in each demonstrator, the knowledge about gripping and robotic manipulation could be used in selecting suitable equipment for lifting and handling of prepreg as well as cured material. In other cases, knowledge gained in one demonstrator could be used in another demonstrator on a more general level. For example, the awareness learned during the first demonstrator about the rigorous quality standards present in the aerospace industry, and how they can affect the type of off-the-shelf solutions that can be used, made the mapping of quality standards an important part of the 
introductory work with the subsequent demonstrators. Many of the results however are case-specific and might be hard to generalize. According to Potts (1993), the difficulty in generalizing results when working on real-life problems in an industrial context can be expected.

The demonstrator-centered research approach has shown great value in the work presented in this licentiate thesis. The research approach can, however, be further developed into a more extensive framework including methodologies suitable for the separate stages, and a more detailed definition of the demonstrator term and suitable subgroups to the term. The process of developing conceptual demonstrators to place the enabling technologies and enabling methods in context, and then realizing the enabling technologies and methods as physical demonstrators, is also important to further develop and elucidate.

\subsection{CONTRIBUTION TO ACADEMIA}

According to Jonsson (2013), the demonstrator-centered research approach is useful in bridging the gap between the academic and the industrial domains, since the demonstrators are based on an industrial problem and are generally developed in collaboration with industrial partners. The research approach provides the academic participants with valuable insights into industrial problems as well as on how new technology is developed within industry. The work, carried out using the demonstrators, is conducted based on a scientific approach and strives to create new knowledge. This knowledge gained directly from the demonstrators as well as from the industrial collaboration in general is documented and presented to the academic community (Jonsson, 2013).

The work presented in this licentiate thesis shows that the demonstratorcentered research approach is suitable for the type of research described herein, and that it can generate knowledge that is valid for both industry and academia. The research approach has been shown to generate both detailed knowledge from the experimentation and evaluation of demonstrators as well as more general knowledge of the industrial context. Some additions to the demonstrator-centered research approach, such as definitions of product and technology demonstrators and an overall description of how conceptual demonstrators can be divided into enabling technologies and enabling methods, have been made.

Apart from illustrating the applicability of the demonstrator-centered research approach, some other contributions to the academic domain are the description 
of the types of automation used within the industrial partners' current manufacturing processes and the detailed results from each demonstrator. The results stemming from the demonstrators not only show examples of how offthe-shelf solutions can be used; they also provide insights and examples on how many aspects, such as product material and complexity, industrial requirements for product performance, and demands for validation, determine if an automated solution is successful.

\subsection{CONTRIBUTION TO INDUSTRY}

When describing the demonstrator-centered research approach, Jonsson (2013) notes that the industrial partners gain the chance of testing new ideas within research projects that might not have been possible to test in a fully industrial context. This can help to overcome the gap between research and industrial implementation (Jonsson, 2013). The research included in this licentiate thesis is a testament to the statements above. The three conceptual demonstrators, and the physical demonstrators for the enabling technologies and methods in particular, have given the industrial partners a chance to test new ideas for automated manufacturing of composite products. The physical demonstrators have shown that for several of the enabling technologies there are off-the-shelf solutions that can be used, indicating that it is possible to use technology developed for other purposes to automate composite manufacturing. The technical reviews performed in the fields of gripping technologies, ultrasonic cutting, automated adhesive dispensing, surface preparation and cleaning has been fed back to the industrial partners, increasing their knowledge in the respective fields. The work on automating the industrial partners' manufacturing has introduced a production engineering perspective in general, and an automation perspective in particular, to an area that traditionally is focused on materials and the properties of the final products. It has also helped to increase the awareness about off-the-shelf solutions for automated composite manufacturing and raised the knowledge level. This can help the industrial partners in writing specifications for purchasing this type of equipment, or for initiating further developments within the field of automated composite manufacturing using off-the-shelf solutions.

\subsection{FUTURE RESEARCH}

The approach to use off-the-shelf solutions for automating composite manufacturing is fairly new, and little published material is found on the topic. The lack of published material, the increased need for composite manufacturing and the interest from industrial partners all point to an area that needs to be 
further explored. The results from this licentiate thesis show several possible lines for future development, both on detailed technological development of certain technologies, on how to generalize results from one demonstrator to another, and on how to be able to build automated solutions for composite manufacturing that fulfill quality requirements and are easy to validate.

For each of the three conceptual demonstrators, it would be interesting to continue with further development of the enabling technologies and enabling methods that have been addressed thus far. It would also be interesting to develop enabling technologies and enabling methods for the areas of the conceptual demonstrators that have not yet been addressed. By doing so, the conceptual demonstrators could be realized as fully functioning manufacturing cells. This would help to gain further insight into the automation of composite manufacturing using off-the-shelf solutions. It would also provide an opportunity to investigate if the manufacturing cells could be validated for use in an ordinary manufacturing environment, as well as an opportunity to further investigate the economic aspects of using off-the-shelf solutions when automating composite manufacturing.

Further, detailed development to confirm some of the preliminary findings could be undertaken for many of the areas that have been presented. The technology for separating prepreg and backing paper and the peel-off process need to be verified in an industrial context. The same goes for ultrasonic cutting, where the real three-dimensional preform geometry with rounded edges must be tested. The support tooling for this preform shape needs to be developed to fit the need for as little preform deflection as possible, but at the same time making sure that all preform edges are accessible for cutting. Several areas of the third conceptual demonstrator could be covered in greater detail, for example a detailed analysis of the effect of dispensing patterns on the quality of the adhesive joint, or further investigation of the automation potential of the various methods for cleaning and preparing the adherend surfaces for adhesive joining.

Gripping and handling are two areas that have been touched upon in all three conceptual demonstrators. The conceptual demonstrators have illustrated an issue that has not been addressed herein, but is an interesting area for further research. Experiences from the demonstrators show that if a gripping tool needs to handle a great variety of geometrical shapes (in this case only twodimensional shapes are considered) the gripper design becomes more complicated. To handle a multitude of shapes the gripper it traditionally designed with several contact points that can be activated or deactivated, 
depending on if they are needed for a particular part. This generates the need for a large number of gripping points, as well as technology for switching on and off the gripping points as they are needed. It is very interesting to explore if grippers can be designed for handling varying shapes in a way that does not call for today's high complexity. The basic idea of building flexibility into the gripping tool should be challenged. Instead of adding more contact points to be able to handle a greater variety of shapes and thereby further complicate tool design, it might be possible to use the ability of simple reprogramming of industrial robots to solve the flexibility issue.

One area that has been omitted from the three conceptual demonstrators, but will be necessary to address in order to realize the concepts, is automated quality inspection. In order to comply with the current quality standards for composite manufacturing within the aerospace industry it is necessary to integrate quality assurance systems in fully automated manufacturing cells. There are a number of off-the-shelf solutions available, for example different vision systems based on cameras or laser scanning technologies. However, they should be further developed in order to be able to integrate in an automated manufacturing cell.

On a more general level, and with further development of automated composite manufacturing based on off-the-shelf solutions, it would be interesting to investigate if it is possible to develop general guidelines to aid in designing these types of systems. Further work using the demonstrator-centered research approach will provide an opportunity to further develop the research approach into a more comprehensive framework for research within this field. With an increased demand from agencies funding research for more applied research results, in many cases in the form of demonstrators, an extended framework can be a valuable methodological contribution. 


\section{REFERENCES}

The chapter contains the references used in this licentiate thesis. The references include printed publications, such as books and articles from journals or proceedings, as well as electronic publications like web-pages and e-books. 
Adams, R., \& Comyn, J. (2000). Joining using adhesives. Assembly Automation, 20(2), 109-117.

Airbus. Innovative Materials. Available at: http:/www.airbus.com/innovation/proven-concepts/indesign/innovative-materials/ [Homepage of Airbus] [Online] [2014-03-12]

American GFM. US-50 6 Axis Ultrasonic Cutter. Available at: http://www.agfm.com/Cutting/3D_Cutting.htm [Homepage of American GFM] [Online] [2014-05-02]

Angerer, A., Ehinger, C., Hoffmann, A., Reif, W., Reinhart, G., \& Strasser, G. (2010). Automated cutting and handling of carbon fiber fabrics in aerospace industries. Automation Science and Engineering (CASE), 2010 IEEE Conference on, pp. 861-866.

Arnold, G., Zahn, S., Legler, A., \& Rohm, H. (2011). Ultrasonic cutting of foods with inclined moving blades. Journal of Food Engineering, 103(4), 394-400.

Bader, M. G., \& Lekakou, C. (1997) "Processing for laminated structures”, in Mallick, P. K. (Eds.), Composites engineering handbook. New York: Dekker.

Balasubramanian, M. (2014). Composite materials and processing [E-book]

Boeing. 787 Dreamliner Program Fact Sheet. Available at:

http://www.boeing.com/boeing/commercial/787family/programfacts.page [Homepage of Boeing] [Online] [2014-03-12]

Boeing (2014). Boeing Rolls Out First 787 Dreamliner at Increased Production Rate. Available at: http://boeing.mediaroom.com/index.php?s=20295\&item=128953\#assets_117 [News Release, Homepage of Boeing] [Online] [2014-03-14]

Bogue, R. (2008). Cutting robots: A review of technologies and applications. Industrial Robot: An International Journal, 35(5), 390-396.

Brecher, C., Emonts, M., Ozolin, B., Schares, R. (2013).’Handling of preforms and prepregs for mass production of composites", in the proceedings of ICCM19, the $19^{\text {th }}$ International Conference on Composite Materials, 28 July - 2 August, Montreal, Canada.

Broetje Automation (2014). Composite handling system. Available at: http://www.broetjeautomation.de/en/solutions-customer-benefit/equipment/composite-manufacturing/handling/ [Homepage of Broetje Automation] [Online] [2014-08-07]

Broetje Automation (2014b). Composite stacking system (CSS). Available at: http://www.broetjeautomation.de/en/solutions-customer-benefit/equipment/composite-manufacturing/integrated-systemfor-automated-lay-up/ [Homepage of Broetje Automation] [Online] [2014-08-07]

Buckingham, R., \& Newell, G. (1996). Automating the manufacture of composite broadgoods. Composites Part A: Applied Science and Manufacturing, 27(3), 191-200.

Burstein, F. (2002), "System development in information system research”, in Williamson, K. (Eds.), Research methods for students, academics and professionals: Information management and systems (2nd. ed.). Wagga Wagga: Centre for Information Studies.

Campbell, F. C. (2004). Manufacturing processes for advanced composites. Oxford: Elsevier Advanced Technology.

Coriolis Composites. The use of robots for fiber placement. Available at: http://www.corioliscomposites.com/technologie.php [Homepage of Coriolis Composites] [Online] [2014-04-29]

Costa, D., Carreira, J., \& Silva, J. G. (1997). WinFT: Using off-the-shelf computers on industrial environments. 1997 IEEE 6th International Conference on Emerging Technologies \& Factory Automation Proceedings, EFTA '97, 39-41. 
Crossley, R. J., Ratchev, S., \& Smith, A. (2013). Emerging technologies for use in aerospace bonded assemblies. SAE International Journal of Aerospace, 6(2), 383-391.

Crossley, R., Schubel, P., \& Warrior, N. (2012). The experimental determination of prepreg tack and dynamic stiffness. Composites Part A: Applied Science and Manufacturing, 43(3), 423-434.

Dick, B. (1993). You want to do an action research thesis? Available at:

http://www.aral.com.au/resources/arthesis.html [Action Research Resources Homepage] [Online] [2014-03-24]

Dick, B. (1997). Rigour and relevance in action research. Available at:

http://www.aral.com.au/resources/rigour.html [Action Research Resources Homepage] [Online] [201403-24]

Dick, B. (2000). A beginner's guide to action research. Available at:

http://www.aral.com.au/resources/guide.html [Action Research Resources Homepage] [Online] [201403-24]

Dini, G., Fantoni, G., \& Failli, F. (2009). Grasping leather plies by bernoulli grippers. CIRP Annals Manufacturing Technology, 58(1), 21-24.

Dorey, G. (1987). Carbon fibres and their applications. Journal of Physics D: Applied Physics, 20(3), 245.

Ebnesajjad, S. (2008). Adhesives technology handbook (2nd. ed.) [E-book] Norwich, N.Y.: William Andrew Pub.

Flottau. J. (2014). Airbus Eyes A320 Production Rate Rise After Record 2013. Available at: http://www.aviationweek.com/Article.aspx?id=/article-xml/awx_01_13_2014_p0-653903.xml\&p=1\# [Aviation Week Homepage] [Online] [2014-03-14]

Gall, M. D., Borg, W. R., \& Gall, J. P. (1996). Educational research: An introduction (6th. ed.). White Plains, N.Y.: Longman.

Gardiner, G. (2011). A350 XWB update: Smart manufacturing. High-performance composites, 19(5), 54-60.

Gascons, M., Blanco, N., \& Matthys, K. (2012). Evolution of manufacturing processes for fiberreinforced thermoset tanks, vessels, and silos: A review. IIE Transactions (Institute of Industrial Engineers), 44(6), 476-489.

Grant, C. (2006). Automated processes for composite aircraft structure. Industrial Robot, 33(2), 117121.

Groover, M. P. (2008). Automation, production systems, and computer-integrated manufacturing (3rd. ed.). Upper Saddle River, N.J.: Prentice Hall.

Henkel (2008). Loctite Solutions Guide. Available at:

http://www.henkel.com/com/content_data/140353_productcatalogue.pdf [Product guide, Homepage of Henkel] [Online] [2014-04-30]

Henkel Corporation. Henkel surface preparation guide. Available at: http://www.henkelap.com/ase/content_data/LT4536_TT_Aerospace_Surface_Preparation_Guide.pdf [Homepage of Henkel] [Online] [2014-08-13]

Hernon, P. (1991), “The Elusive Nature of Research in LIS”, in McClure, C. R., Hernon, P. (Eds.), Library and information science research: Perspectives and strategies for improvement, Norwood, N.J.: Ablex Publ. Corp.

Hoa, S. V. (2009). Principles of the manufacturing of composite materials. DEStech Publications, Inc. 
Jahn, B. (2013). The global CRP market 2013. Carbon Composites e.V.

Johansson, M., Sundqvist J. (2013). Utveckling och design av gripdon för komposithantering. Department of Machine Design, Linköping University, Sweden. [Report No. LIU-IEI-TEK-A-13/01635-SE].

Jonsson, M. (2013). On manufacturing technology as an enabler of flexibility : Affordable reconfigurable tooling and force-controlled robotics. Department of Manufacturing Engineering, Linköping University, Sweden. [Dissertation No.1501].

Karlsson, K. F., \& Åström, T. B. (1997). Manufacturing and applications of structural sandwich components. Composites Part A: Applied Science and Manufacturing, 28(2), 97-111.

Kolluru, R., Valavanis, K. P., Steward, A., \& Sonnier, M. J. (1995). A flat surface robotic gripper for handling limp material. Robotics \& Automation Magazine, IEEE, 2(3), 19-26.

Kyle, E. (2014). Space launch report: orbital launch summary by year. Available at: http://www.spacelaunchreport.com/logyear.html [Homepage] [Online] [2014-08-07]

Leedy, P. D. (1997). Practical research : Planning and design (6th. ed.). Upper Saddle River, N.J.: Merrill.

Lien, T., \& Davis, P. (2008). A novel gripper for limp materials based on lateral coanda ejectors. CIRP Annals-Manufacturing Technology, 57(1), 33-36.

Lucas, M., MacBeath, A., McCulloch, E., \& Cardoni, A. (2006). A finite element model for ultrasonic cutting. Ultrasonics, 44, e503-e509.

Lucas, M., Petzing, J., Cardoni, A., Smith, L., \& McGeough, J. (2001). Design and characterisation of ultrasonic cutting tools. CIRP Annals-Manufacturing Technology, 50(1), 149-152.

Lukaszewicz, D. H. -. A., Ward, C., \& Potter, K. D. (2012). The engineering aspects of automated prepreg layup: History, present and future. Composites Part B: Engineering, 43(3), 997-1009.

Mallick, P. K. (1997) “Introduction: Definitions, Classifications, and Applications", in Mallick, P. K. (Eds.), Composites engineering handbook. New York: Dekker.

McKinney, D. (1999). Impact of commercial off-the-shelf (COTS) software on the interface between systems and software engineering. pp. 627-628.

Monkman, G., Taylor, P., \& Farnworth, G. (1989). Principles of electroadhesion in clothing robotics. International Journal of Clothing Science and Technology, 1(3), 14-20.

Newell, G. C., Buckingham, R. O., \& Khodabandehloo, K. (1996). The automated manufacture of prepreg broadgoods components - A review of literature. Composites Part A: Applied Science and Manufacturing, 27(3 PART A), 211-217.

Nunamaker, Jr., J. F., Chen, M., \& Purdin, T. D. M. (1990). Systems development in information systems research. Journal of Management Information Systems, 7(3), 89.

Oosthuizen, M.J.H. (2002), “Action Research", in Williamson, K. (Eds.), Research methods for students, academics and professionals: Information management and systems (2nd. ed.). Wagga Wagga: Centre for Information Studies.

OK International. DX-250 Series. Available at: http://www.testequipmentdepot.com/okinternational/pdf $/ \mathrm{dx}$-250_data.pdf [Product datasheet, Homepage of Test Equipment Depot] [Online] [2014-04-30]

Owen, M., Middleton, V., \& Rudd, C. (1990). Fibre reinforcement for high volume resin transfer moulding (RTM). Composites Manufacturing, 1(2), 74-78. 
Ozcelik, B., Erzincanli, F., \& Findik, F. (2003). Evaluation of handling results of various materials using a non-contact end-effector. Industrial Robot: An International Journal, 30(4), 363-369.

Potts, C. (1995). Invented requirements and imagined customers: Requirements engineering for off-theshelf software. Proceedings of 1995 IEEE International Symposium on Requirements Engineering (RE'95), 128-130.

Potts, C. (1993). Software-engineering research revisited. IEEE Software, 10(5), 19-28.

Putnam, J. W., Seferis, J. C., Pelton, T., \& Wilhelm, M. (1995). Perceptions of prepreg tack for manufacturability in relation to experimental measures. Science and Engineering of Composite Materials, 4(3), 143-154.

Reinhart, G., \& Straßer, G. (2011). Flexible gripping technology for the automated handling of limp technical textiles in composites industry. Production Engineering, (5), 301-306.

Schneider, Y., Zahn, S., Schindler, C., \& Rohm, H. (2009). Ultrasonic excitation affects friction interactions between food materials and cutting tools. Ultrasonics, 49(6-7), 588-593.

Stephan, J., \& Seliger, G. (1999). Handling with ice-the cryo-gripper, a new approach. Assembly Automation, 19(4), 332-337.

Taylor, P. M. (1995). Presentation and gripping of flexible materials. Assembly Automation, 15(3), 33 35.

Thoe, T., Aspinwall, D., \& Wise, M. (1998). Review on ultrasonic machining. International Journal of Machine Tools and Manufacture, 38(4), 239-255.

Ulrich, K. T., \& Eppinger, S. D. (2008). Product design and development (4. ed. ed.). Boston, Mass.: McGraw-Hill/Irwin.

Upton, D. M. (1994). The Management of Manufacturing Flexibility. California Management Review, vol. 36(2), 72-89.

Ward, C., Bhatnagar, V., Potter, K. (2013) "Developing an Automated System for the Removal of Protective Films from Pre-Preg Material, to Remove a Manufacturing Bottleneck in Terms of Pick and Place Automation", presented at SAMPE SETEC 13, 11-12 September 2013, Wuppental, Germany.

Williamson, K., Burstein, F., \& McKemmish, S. (2002), "Introduction to research in relation to professional practice", in Williamson, K. (Eds.), Research methods for students, academics and professionals: Information management and systems (2nd. ed.). Wagga Wagga: Centre for Information Studies.

Williamson, K., Burstein, F., \& McKemmish, S. (2002b), "The two major traditions of research", in Williamson, K. (Eds.), Research methods for students, academics and professionals: Information management and systems (2nd. ed.). Wagga Wagga: Centre for Information Studies.

Wingfield, J. (1993). Treatment of composite surfaces for adhesive bonding. International Journal of Adhesion and Adhesives, 13(3), 151-156.

Åström, B. T. (2002). Manufacturing of polymer composites (New ed.). Cheltenham: Nelson Thornes. 


\section{APPENDED PAPERS}

This chapter contains the four articles that are appended to this licentiate thesis. 

Paper I

Björnsson, A., Lindbäck, J. E., \& Johansen, K (2013). Automated Removal of Prepreg Backing Paper - A Sticky Problem

Andreas Björnsson initiated and wrote the paper based on data collected in close collaboration with Jan Erik Lindbäck, who contributed with industrial expertise as well as developed and built a prototype for automated mechanical bending of prepreg. Kerstin Johansen supported and guided the writing process.

Paper II

Björnsson, A., Johansen, K., \& Alexandersson, D. (2013) Three-Dimensional Ultrasonic Cutting of RTM Preforms - A Part of a High Volume Production System

Andreas Björnsson wrote the paper and performed the literature review. The technology review and test plan development, as well as the empirical tests were carried out in collaboration between Andreas Björnsson and Dan Alexandersson who also aided in developing the specifications for the demonstrator. Kerstin Johansen supported the development of the test plan and the writing of the paper.

Paper III

Björnsson, A., Thuswaldner, M., \& Johansen, K. (2014) Automated Composite Manufacturing Using Off-the-shelf Automation Equipment - A Case from the Space Industry

Andreas Björnsson initiated and wrote the paper based on information partly collected during student projects that were supervised by Andreas as well as on data directly collected by Andreas. Michael Thuswaldner helped in developing the demonstrator specifications and Kerstin Johansen supported and gave input to the demonstrator development as well as the writing process.

Paper IV

Björnsson, A. \& Johansen, K. (2012) Composite Manufacturing: How Improvement Work Might Lead to Renewed Product Validation

Andreas Björnsson performed the literature review in the field of change management, collected the data through interviews and observations and wrote the paper. Kerstin Johansen supported the data analysis and the writing processes. 



\section{Appended Papers}

The articles associated with this thesis have been removed for copyright reasons. For more details about these see:

http://urn.kb.se/resolve?urn=urn:nbn:se:liu:diva-111936 